Article

\title{
Low-Cost Synthesis of Alumina Nanoparticles and Their Usage for Bisphenol-A Removal from Aqueous Solutions
}

\author{
Ollé Rodrigue $\operatorname{Kam}^{1}$, Issaka Garikoe ${ }^{1}$, Corneille Bakouan ${ }^{1,2} \mathbb{D}$ and Boubié Guel ${ }^{1, *}$ \\ 1 Laboratory of Materials and Molecular Chemistry, UFR—SEA, University Joseph Ki Zerbo, \\ Ouagadougou 03 BP 7021, Burkina Faso; kamollrodrigue@yahoo.fr (O.R.K.); garikoe@yahoo.fr (I.G.); \\ bakouancorneille@gmail.com (C.B.) \\ 2 Training and Research Unit in Science and Technology, University of Ouahigouya, \\ Ouahigouya 01 BP 346, Burkina Faso \\ * Correspondence: boubieguel@yahoo.fr; Tel.: +226-76-645-469; Fax: +226-50-307-242
}

check for

updates

Citation: Kam, O.R.; Garikoe, I.; Bakouan, C.; Guel, B. Low-Cost Synthesis of Alumina Nanoparticles and Their Usage for Bisphenol-A Removal from Aqueous Solutions. Processes 2021, 9, 1709. https:// doi.org/10.3390/pr9101709

Academic Editors: Taleb Ibrahim, Mustafa Khamis, Isaac Wait and Valentin Nenov

Received: 30 August 2021

Accepted: 17 September 2021

Published: 24 September 2021

Publisher's Note: MDPI stays neutral with regard to jurisdictional claims in published maps and institutional affiliations.

Copyright: (c) 2021 by the authors. Licensee MDPI, Basel, Switzerland. This article is an open access article distributed under the terms and conditions of the Creative Commons Attribution (CC BY) license (https:/ / creativecommons.org/licenses/by/ $4.0 /)$.

\begin{abstract}
Gamma-alumina nanoparticles ( $\gamma$ ANPs) were obtained from a low-cost process by using natural bauxites. The $\gamma$ ANPs materials were characterized by $\mathrm{X}$-ray powder diffraction (XRPD), Fourier-transform infrared spectroscopy (FTIR), Brunauer-Emmett-Teller (BET) theory, scanning electron microscopy (SEM), atomic force microscopy (AFM), and were functionalized with N-cetyl-N, $\mathrm{N}, \mathrm{N}$, trimethylammonium bromide (CTAB), leading to CTAB modified $\gamma$-alumina nanoparticles ( $\gamma$ ANPs-CTAB). These novel functionalized $\gamma$ ANPs-CTAB were characterized by XRPD, FTIR, and were used as an adsorbent for bisphenol-A (BPA) removal from water. Batch investigations were conducted under different experimental conditions (e.g., adsorbent dose, agitation time, initial concentration, and $\mathrm{pH}$ and surfactant loading) in order to optimize BPA adsorption and to identify the adsorption mechanisms in the system $\gamma$ ANPs-CTAB-BPA. The effect of $\mathrm{pH}$ on the adsorption showed that the quantity of BPA removed increased remarkably until the $\mathrm{pH}$ value was 4 , then remained almost constant until the $\mathrm{pH}$ value was up to 10 , and then decreased for $\mathrm{pH}$ values greater than 10. For an initial BPA concentration of $20 \mathrm{mg} / \mathrm{L}$ and an adsorbent dose of $12.5 \mathrm{~g} / \mathrm{L}$ at a pH value of 10 , the removal efficiency achieved was $91.80 \pm 0.21 \%$. The adsorption mechanism was perfectly described by pseudo-second-order kinetics and the Langmuir isotherm. $\gamma$ ANPs-CTAB materials were found to be effective adsorbents for BPA removal from water.
\end{abstract}

Keywords: N-cetyl-N, N, N, trimethylammonium bromide; surfactant; endocrine disrupting chemical; gamma-alumina nanoparticles

\section{Introduction}

Bisphenol-A (BPA) is an organic compound widely used as a monomer in the production of polycarbonates and epoxy resins [1-3], which are used primarily in food plastic containers, surface coatings for food and water containers, baby bottles, cans, appliances, dyes, and coatings. It is also used as an antioxidant in plasticizers and as a polymerization inhibitor in polyvinyl chloride (PVC). Unfortunately, BPA is an estrogen-mimetic endocrine disruptor capable of mimicking natural hormones, leading to negative health effects including heart disease, diabetes, reproductive problems, early puberty, obesity, genital malformations, and cancer [4,5]. Pop et al. reported that BPA can also act with the lipids in the tissue of vegetal organisms, and this induces cell membrane modification, or its damage, and eventually apoptosis [6]. This compound is particularly dangerous for pregnant women, infants, young children, and adolescents during puberty $[7,8]$. In developing countries, several industries constitute a source of BPA pollution in groundwater and wastewaters and a source of exposure for humans in the located towns. Unfortunately, in sub-Saharan Africa, poverty and weak state institutions inhibit strict control of endocrine disruptors that are released into the environment through the release of wastewaters. Although several local industries are currently using BPA in their production (plastic bottle 
production, dyes and coatings, etc.), the release of BPA into the environment is not regulated. In this context, there is an urgent need to find cost-effective and reliable methods for BPA removal from groundwater and wastewater.

Different reliable methods, such as adsorption $[9,10]$, chemical advanced oxidation [11], membrane filtration [12], electrochemical mineralization [13,14], ozonation [15], Fenton degradation [16], photocatalytic decomposition [17], $\mathrm{UV} / \mathrm{H}_{2} \mathrm{O}_{2}$ oxidation [18], and biodegradation [19], have been used for BPA removal from complex aqueous matrices. Advanced oxidation processes are related to the combination of activated carbon and $\mathrm{O}_{3} / \mathrm{UV}$ and $\mathrm{O}_{3} / \mathrm{UV} / \mathrm{TiO}_{2}$ systems for BPA removal [11]. However, the presence of ozone involved higher costs associated with the treatment. In membrane filtration, selected polyamide-based dense nanofiltration (NF) and reverse osmosis (RO) membranes were compared for their BPA rejections from a model solution of $50 \mathrm{mg} / \mathrm{L}$ at 10 bars of applied pressure [12]. Electrochemical oxidation, involving consumption of electric energy with anode electrodes, which are not easily accessible in a defined context, was used for BPA removal $[13,14]$. Moreover, for such an operation, a qualified and trained staff is required. Consumption of electric energy was also involved in photolytic degradation experiments of BPA by using $\mathrm{Bi}_{2} \mathrm{WO}_{6}$ samples in a photochemical reactor with simulated sunlight irradiation provided by an $800 \mathrm{~W}$ xenon lamp [17], and in a mineralization process by integrating ultrasound-UV-iron (II) treatment [18]. Ozonation involves the application of ozone for the treatment of BPA [15]. Although this treatment presented a great potential for industrial scale, there was a significant lack of information on the formation of oxidation by-products and their toxicities, particularly in a more complex medium such as wastewater, and further investigation was needed for a better understanding of the environmental fate of BPA [15]. Oxidative degradation using hydroxyl radicals $\left(\mathrm{OH}^{\bullet}\right)$ was proven to be an efficient approach by using a Fenton system consisting of the Au/styrene-based activated carbon catalyst and hydrogen peroxide $\left(\mathrm{H}_{2} \mathrm{O}_{2}\right)$ for the degradation of BPA under non-photo-induced conditions [16]. As for biodegradation, the abilities of ligninolytic fungal strains to degrade several typical representatives of EDCs were investigated [19]. The results showed that almost all the fungi were able to degrade the tested EDCs under the study's conditions. However, the study emphasized the need for further research, especially to identify metabolites, intermediates, and degradation products, in order to improve the understanding of the degradation mechanisms and to assess the toxicological risks related to the degradation processes of EDC. All of the above techniques may appear to be difficult to implement in developing countries, because of one or a combination of the following reasons: (i) high cost; (ii) sophisticated technology requiring highly qualified and trained staff; (iii) toxicity risks in some cases. On the contrary, the adsorption process onto appropriate adsorbents is strongly favored because of its simplicity, cost effectiveness, ease of operation, and high efficiency for BPA removal $[9,10,20]$. Moreover, the process could be applicable for a large amount of water and can be implemented in rural environments. In particular, there is a need for finding effective, inexpensive, and efficient materials for the adsorption processes. The removal of BPA from aqueous solutions by adsorption was demonstrated in several investigations, including hydrophobic zeolite [20,21], cetylpyridinium bromide (CPB) and N-cetyl-N, N, N, trimethylammonium bromide (CTAB) modified natural zeolites [21-23], various surfactants-modified clays [24-26], combined use of biopolymer chitosan and oxidoreductase polyphenol oxidase [27], chitosan [28], waste biomass [29-31] composites and polymeric materials [32,33], nano-adsorbents materials such as 2-vinylpyridine functionalized magnetic nanoparticles [34], and graphene oxide [35]. Among the nano-adsorbents used for organic and inorganic pollutants removal, gamma-alumina nanoparticles have gained extensive attention as reliable, sustainable, and eco-friendly materials [36-43]. Gamma-alumina nanoparticles with a high specific surface area were found to be very promising for the removal of hazardous dyes, such as azo dyes and Orange G, from aqueous solutions [41,43]. However, due their negative charge surface, recalcitrant pollutants are very hard to remove by adsorption on them. Fortunately, the modification of their surface, by suitable surfactants, enhances their structural properties, 
increases their potential as adsorbents, and greatly improves the removal of both inorganic and organic pollutants [36-40,42]. Among the various surfactants that were used for adsorbents surface modification in view of BPA removal from aqueous solutions [22,23,44], CTAB was found to be very efficient for adsorbent nanoparticle modification. CTAB was used by Zhang et al. for the first time for the modification of synthesized $\mathrm{SiO}_{2}$ from tetraethyl orthosilicate by a sol-gel method, and the modified silica nanoparticles were applied to adsorb BPA [44]. Recently, Suzimara Rovani et al. reported a fast, efficient, and clean adsorption of BPA using N-cetyl-N, N, N, trimethylammonium (CTAB) modified mesoporous silica nanoparticles from sugarcane waste ash [45]. Although the above literature review shows that the method of surface modification is a well-established method that enhances the structural properties of the materials in view of environmental applications, synthesized gamma-alumina nanoparticles, obtained through a low-cost process by using natural materials such as bauxite and subsequently modified with different surfactants, have not been completely explored as potential adsorbents for the removal of BPA from aqueous solutions. Indeed, the quest for simple, low-cost, and high-performance water purification processes in developing countries necessitates the use of local materials that are natural materials, good sorbents, inexpensive, and represent a viable replacement for high cost starting materials and toxic precursors that are involved in synthesis processes. In particular, large deposits of bauxite ores are available in the Center-North region of Burkina Faso, bauxite being known, among other raw materials (kaolin, mica, and fly ash), as the best source of aluminum for the synthesis of nano gamma-alumina powder [46,47]. In this regard, special attention is deserved for the low-cost synthesis of surfactant modified gamma-alumina nanoparticles for BPA removal from aqueous solutions.

To obtain gamma-alumina nanoparticles of desired size, shape, and functionalities, several chemical routes have been used, such as hydrothermal, vapor phase reaction, coprecipitation, combustion, and sol-gel methods [48-50]. Among these various routes, the sol-gel process achieves a high purity phase, good compositional homogeneity, and a high surface activity of synthesized alumina nanoparticles [51,52]. In this study, gamma-alumina nanoparticles ( $\gamma$ ANPs) were obtained from a low-cost process with the sol-gel process by using natural local bauxites from Burkina Faso. Bauxite is a heterogeneous material that occurs naturally and is primarily made up of one or more aluminum hydroxide minerals, plus various mixtures of silica $\left(\mathrm{SiO}_{2}\right)$, iron oxide $\left(\mathrm{Fe}_{2} \mathrm{O}_{3}\right)$, titanium dioxide $\left(\mathrm{TiO}_{2}\right)$, aluminosilicate, and trace amounts of several impurities [47]. The principal aluminum hydroxide minerals found in varying proportions within bauxite are gibbsite $\left(\mathrm{Al}(\mathrm{OH})_{3}\right)$ and the polymorphs boehmite and diaspore (both $\mathrm{AlO}(\mathrm{OH})$ ). To our knowledge, few studies on the synthesis of gamma nano-alumina from natural local bauxite for water pollution control have been reported. This paper is the first one that investigates the removal of BPA from modified synthesized gamma-alumina nanoparticles obtained from natural local bauxites.

The objective of the present paper was: (i) to increase the added value of the natural local bauxites that are abundant and widely available in Burkina Faso by using them in the preparation of gamma-alumina nanoparticles ( $\gamma$ ANPs), and subsequently to investigate the physicochemical properties of CTAB-functionalized $\gamma$ ANPs ( $\gamma$ ANPs-CTAB); (ii) to investigate the removal of BPA from aqueous solutions by adsorption onto $\gamma$ ANPs-CTAB, with a particular emphasis on the following effects: adsorbent dosage, contact time (kinetics), initial concentration (isotherms), effect of $\mathrm{pH}$, and effect of surfactant loading. The $\gamma$ ANPs materials were characterized by Brunauer-Emmett-Teller (BET) theory, scanning electron microscopy (SEM), and atomic force microscopy (AFM). The novel functionalized CTAB $\gamma$-alumina nanoparticles ( $\gamma$ ANPs-CTAB) were also characterized by X-ray powder diffraction (XRPD), scanning Electron Microscopy (SEM) and Fourier-transform infrared spectroscopy (FTIR). 


\section{Materials and Methods}

\subsection{Materials}

The natural local bauxite, named BA, used for the synthesis of $\gamma$-alumina nanoparticles ( $\gamma$ ANPs), was collected in Foulou village located in the Center-North region of Burkina Faso at the following coordinates: $13^{\circ} 13^{\prime} 35,0^{\prime \prime} \mathrm{N}$ and $01^{\circ} 32^{\prime} 56,7^{\prime \prime} \mathrm{W}$. Hydrochloric acid ( $\mathrm{HCl}, 37 \%$ extra pure, Loba Chemie, Ahmedabad, India), ethanol (99.8\%, Fluka, Darmstadt, Germany) and ammonia solution (32\%, BDH, Londres, UK) were used to prepare and modify the $\gamma$-alumina nanoparticle materials. The surfactant N-cetyl-N, N, N, trimethylammonium bromide (CTAB) was purchased from Sigma-Aldrich ( $\geq 99 \%$ purity). Silver nitrate $\left(\mathrm{AgNO}_{3} \geq 99.8 \%\right.$ purity) was purchased from Sigma-Aldrich to test the bromide ions.

The analytical grade acetonitrile $\left(\mathrm{CH}_{3} \mathrm{CN} \geq 99 \%\right.$ purity) and sodium hydroxide pellets ( $\mathrm{NaOH} \geq 99 \%$ purity) were purchased from Sigma-Aldrich and VWR International, respectively. Hydrophilic PTFE, or Acrodisc nylon filters, were purchased from Sigma Aldrich. Milli-Q water used for all experiments was produced by the Milli-Q (Millipore Corporation, New York, NY, USA) water purification system.

\subsection{Methods}

\subsubsection{Synthesis and Modification of Gamma-Alumina Nanoparticles ( $\gamma$-ANPs)}

The adsorbent material gamma nano-alumina ( $\gamma$ ANPs) was prepared from natural local bauxite by using the sol-gel process according to Dani Gustaman Syarif et al., 2015 and P. Manivasakan et al., 2009 [46,53]. The bauxite materials were first dried, crushed, ground, and sieved. The passers-by of a sieve with a mesh size of $75 \mu \mathrm{m}$ were selected for the synthesis of $\gamma$ ANPs. A very dry mixture containing $60 \%$ by mass of raw bauxite and $40 \%$ by mass of sodium hydroxide was allowed to react in $250 \mathrm{~mL}$ of distilled water and vigorously stirred at $800 \mathrm{rpm}$ for $2 \mathrm{~h}$. The idea was to obtain a $\mathrm{pH}$ in the range of $13-14$, a $\mathrm{pH}$ range in which only aluminum oxide was dissolved whereas iron oxide, titanium oxides, and other oxides were deposited as sludge. Thus, the stirred solution was centrifuged, and the supernatant was collected and centrifuged several times to finally obtain a fairly clear solution. This filtrate was used as a precursor for the synthesis of $\gamma$ ANPs. The reaction likely to occur between bauxite and soda is the following (Equation (1)):

$$
\text { Bauxite }+\mathrm{NaOH}+\text { water } \rightarrow \mathrm{NaAlO}_{2}+\text { red mud }+ \text { water }
$$

The obtained filtrate was first brought to room temperature and then a solution of N-cetyl-N, N, N, trimethylammonium bromide (CTAB) was added, drop by drop, to the filtrate under constant stirring. The role of CTAB is to minimize the formation of agglomerations. Hydrochloric acid was then added to the filtrate to initiate flocculation. We noted the efficiency of the flocculation in the $\mathrm{pH}$ range 6.5-9. The resulting gel was filtered and washed several times with distilled water and then with ethanol to remove impurities. The resulting gel was aged at $200{ }^{\circ} \mathrm{C}$ for $10 \mathrm{~h}$ in an oven to obtain the boehmite. The boehmite was then calcined at $900{ }^{\circ} \mathrm{C}$ for $4 \mathrm{~h}$ and finally crushed using agate mortar and pestle to get the fine homogeneous powder of the $\gamma$ ANPs.

\subsubsection{Preparation of Gamma-Alumina Nanoparticles ( $\gamma$ ANPs) Modified by CTAB $(\gamma$ ANPs-CTAB)}

CTAB as the stabilizer plays an important role in the velocity of adsorption, which depends on the physicochemical characteristics of the system adsorbate, adsorbent, and solution. In this case, the surfactant $\mathrm{CTAB}$ has a positive charge and therefore shows affinity for anionic species [54,55]. Considering the methodology utilized, it is expected to find CTAB on the surface of the gamma-alumina nanoparticles making the surface hydrophobic, which provides suitable sites for BPA adsorption.

To prepare the CTAB modified $\gamma$-ANPs, an amount of $\gamma$-ANPs and CTAB was mixed. CTAB was first dissolved in a mixture composed of water and ethanol $(1: 1, v / v)$. To this emulsion/biphasic system, the nano-alumina obtained previously was added, under constant stirring. The $\mathrm{pH}$ of this suspension was adjusted at the range from 9.0 to 10 by 
addition of ammonia solution $\left(0.1 \mathrm{~mol} \mathrm{~L}^{-1}\right)$. The mixed solution was shaken for $1 \mathrm{~h}$ and then heated at $60^{\circ} \mathrm{C}$ for $5 \mathrm{~h}$. The $\gamma$-ANPs-CTAB were separated from the reaction medium under centrifugation and washed several times with pure water and oven-dried at $105{ }^{\circ} \mathrm{C}$. This product ( $\gamma$ ANPs-CTAB) was used as sorbent for BPA and BPA ions.

\subsubsection{Characterization Methods}

Elementary chemical analysis was performed by ICP (ICP-AES-IRIS Intrepid II XSP model). The solution was made as follows: $100 \mathrm{mg}$ of samples (natural local bauxite or $\gamma$ ANPs) previously dried in an oven at $105^{\circ} \mathrm{C}$ for $24 \mathrm{~h}$ were weighed and then placed in a Teflon case. To this we added $3 \mathrm{~mL}$ of hydrofluoric acid (HF $30 \% w / w), 3 \mathrm{~mL}$ of sulfuric acid $\left(\mathrm{H}_{2} \mathrm{SO}_{4} 96 \% w / w\right)$, and $4 \mathrm{~mL}$ of nitric acid $\left(\mathrm{HNO}_{3} 65 \% w / w\right)$. The whole was placed in the microwave oven of the MILESTONE/START D Microware brand, which was brought to $200{ }^{\circ} \mathrm{C}$ for twenty minutes. After mineralization, the samples were filtered, and the filtrates were diluted and then analyzed. The values output from the ICP were added to obtain the total chemical composition of sample.

The specific surface area and pore volume of the $\gamma$ ANPs samples were determined by the BET analysis using the BELSORP MAX instrument running with the Bel Japan Inc. software. The samples were degassed and dehydrated for $24 \mathrm{~h}$ at $200{ }^{\circ} \mathrm{C}$ under vacuum. The method used is based on the nitrogen adsorption/desorption isotherms at $77 \mathrm{~K}$.

Scanning electron microscopy (SEM HITACHI SU8020 computer-controlled with the software EDX SDD, Thermo Scientific, Mons, Belgium) was used for the morphological characterization of the samples ( $\gamma$ ANPs, $\gamma$ ANPs-CTAB, and $\gamma$ ANPs-CTAB-BPA). The working potential was $20 \mathrm{kV}$, which allowed a magnification of up to 30,000 X. The SEM was coupled with an EDX (software EDX SDD Thermo Scientific) for chemical analysis of sample surfaces. The powdered samples with a particle size of less than $100 \mu \mathrm{m}$ were placed on double-sided sticky paper, which in turn was glued to the sample holder. The whole was metallized with a layer of gold $(\mathrm{Au} / \mathrm{Ag})$ to make it conductive before observation. To quantitatively estimate the particle size, the surface roughness, and visualize the surface nano-texture of the pure $\gamma$ ANPs samples, AFM analysis was carried using Multimode $8+$ Nanoscope V controller (Bruker) microscope. A solution of PMMA $(\mathrm{Mn} \sim 18,000)$ $15 \mathrm{mg} \cdot \mathrm{mL}^{-1}+\gamma$ ANPs $10 \mathrm{mg} \cdot \mathrm{mL}^{-1}$ in chlorobenzene was spin coated at $4000 \mathrm{rpm}$ on a glass substrate cleaned beforehand and then dried with nitrogen. The sample was then annealed on a hot plate at $100{ }^{\circ} \mathrm{C}$ for $5 \mathrm{~min}$. The AFM analysis was then carried out.

The adsorbent materials $\gamma$ ANPs and $\gamma$ ANPs-CTAB, and the samples after BPA adsorption ( $\gamma$ ANPs-CTAB-BPA), were characterized by X-ray powder diffraction (XRPD) on a D8 Advance Davinci Bruker X-ray generator diffractometer (working at $40 \mathrm{~mA}$ generator current and $40 \mathrm{kV}$ generator voltage with $\mathrm{Cu}-\mathrm{K} \alpha$ radiation $(\lambda=1.54060 \AA))$. The XRPD data were recorded in the $2 \theta$ range $5-70^{\circ}$ at a scan speed of $0.02^{\circ} \mathrm{s}^{-1}$.

To identify functional groups on the samples ( $\gamma$ ANPs, $\gamma$ ANPs-CTAB, or $\gamma$ ANPs-CTABBPA), Fourier-transform infrared (FTIR) spectroscopy was performed using a Shimadzu FTIR-8400S spectrometer. The spectra were acquired by accumulating 20 scans with a resolution of $4 \mathrm{~cm}^{-1}$ over a wavelength range of 400 to $4000 \mathrm{~cm}^{-1}$. The measurements were carried out in absorbance. Infrared analysis of the samples was performed using the potassium bromide pelletizing technique. The pellets were made by mixing $5 \mathrm{mg}$ of each sample with $500 \mathrm{mg}$ of potassium bromide (KBr, Merck, Darmstadt (Germany)). The mixture obtained was finely ground and subjected to a pressure of ten (10) tons. The pellet thus formed was analyzed with a spectrophotometer.

\subsubsection{Determination of $\mathrm{pH}_{\mathrm{ZPC}}$}

To understand the adsorption mechanism, it is necessary to determine the zero charge point of the adsorbent [56,57]. $\mathrm{pH}_{\mathrm{ZPC}}$ of an adsorbent is an important characteristic, as it helps in determining the $\mathrm{pH}$ value at which the surface of the adsorbent becomes electrically neutral and facilitates predicting the surface behavior of adsorbent materials. To determine the $\mathrm{pH}_{\mathrm{ZPC}}$, the solid addition method was adopted using $0.01 \mathrm{M}$ of $\mathrm{NaCl}$. A volume of 
$50 \mathrm{~mL}$ of this solution was placed in different flasks, each containing $200 \mathrm{mg}$ of alumina nanoparticles at different $\mathrm{pH}$ values. The $\mathrm{pH}$ of the solutions was adjusted in 2.0-12.0 range by adding $0.1 \mathrm{~mol} \cdot \mathrm{L}^{-1}$ of $\mathrm{HCl}$ or $\mathrm{NaOH}$ solutions. The flasks were then agitated at $500 \mathrm{rpm}$ for $24 \mathrm{~h}$, and the $\mathrm{pH}$ of the solutions was measured by a $\mathrm{pH}$ meter. A graph of $\mathrm{pH}_{\text {final }}$ vs. $\mathrm{pH}_{\text {initial }}$ was plotted and the point of intersection of the two graphs represents the $\mathrm{pH}_{\mathrm{ZPC}}$ of the alumina nanoparticles. At $\mathrm{pH}$ values below $\mathrm{pHzpc}$, the surface of the adsorbent is positively charged; at values greater than $\mathrm{pHzpc}$, the surface of the adsorbent is negatively charged.

\subsection{Batch Bisphenol-A (BPA) Adsorption Investigations}

The adsorption studies of BPA onto $\gamma$ ANPs-CTAB were conducted at different $\mathrm{pH}$ values and various initial BPA concentrations. The experiments were carried out by agitating the BPA solution with $\gamma$ ANPs-CTAB (adsorbent dosage varying from $0.1 \mathrm{~g}$ to $1 \mathrm{~g}$ ) under a defined constant stirring speed at different contact times varying from 0 to $120 \mathrm{~min}$.

All batch experiences were carried out in triplicate at room temperature. The concentration of BPA before and after adsorption was measured by a high-performance liquid chromatography (HPLC, Agilent HP 1100) system coupled with a Luna $5 \mu \mathrm{L}$ C18 column (Phenomenex Pty Ltd., Lane Cove, (Australia)). A DAD (UV-visible) detector was used to determine the concentration of BPA in the supernatants. After agitation in all cases, the solution was centrifuged at $4000 \mathrm{rpm}$ and the suspension was filtered through $0.45 \mu \mathrm{m}$ nylon Acrodisc or hydrophilic PTFE membrane filters. The mobile phase was a mixture of acetonitrile and deionized water $(V / V)$ and the detection wavelength was $278 \mathrm{~nm}$. A flow rate of $0.1 \mathrm{~mL} / \mathrm{min}$ and an injection volume of $20 \mu \mathrm{L}$ were employed for the analyses.

The amount of the adsorbed BPA $(\mathrm{mg} / \mathrm{g})$ in all the experiments was calculated using the Equation (2):

$$
\mathrm{Qe}(\mathrm{mg} / \mathrm{g})=[(\mathrm{Ci}-\mathrm{Ce}) \times V] / M \times 1000
$$

$\mathrm{C}_{\mathrm{i}}$ and $\mathrm{C}_{\mathrm{e}}$ are initial and equilibrium concentrations of BPA $(\mathrm{mg} / \mathrm{L})$, respectively, $V$ is the volume $(\mathrm{mL})$, and $M$ is the adsorbent mass $(\mathrm{g})$.

The percentage of BPA (\% BPA) removed is calculated using the Equation (3):

$$
\% \mathrm{BPA}=[(\mathrm{Ci}-\mathrm{Ce}) \times 100] / \mathrm{Ci}
$$

$\mathrm{C}_{\mathrm{i}}$ and $\mathrm{C}_{\mathrm{e}}$ are initial and equilibrium concentrations of BPA (mg/L), respectively.

The $\mathrm{pH}$ value of all solutions used for BPA adsorption experimentation was adjusted to a $\mathrm{pH}$ value around 10 .

The effect of the surfactants loading level on the BPA adsorption was carried out by placing $500 \mathrm{mg}$ of the resulting $\gamma$ ANPs-CTAB with the CTAB loaded at various percentages $(5,10,15,20,25,30,35$ and 40$)$ and $40 \mathrm{~mL}$ of BPA solution at the concentration of $20 \mathrm{mg} / \mathrm{L}$, and the whole was stirred at $600 \mathrm{rpm}$ for $24 \mathrm{~h}$.

The $\mathrm{pH}$ effect on the adsorption of BPA was carried out by adjusting the $\mathrm{pH}$ of a solution of $20 \mathrm{mg} / \mathrm{L}$ from $\mathrm{pH}$ 2-12 and further $40 \mathrm{~mL}$ of each prepared solution and $200 \mathrm{mg}$ of $\gamma$ ANPs-CTAB were placed in a bottle of $60 \mathrm{~mL}$ and the whole was shaken for $24 \mathrm{~h}$ with a horizontal shaker.

The effect of the adsorbent dose was investigated by the addition of different amounts of $\gamma$ ANPs-CTAB (from 0.1 to $1.0 \mathrm{~g}$ ) in $40 \mathrm{~mL}$ of $20 \mathrm{mg} / \mathrm{L} \mathrm{BPA}$ aqueous solution at $298 \mathrm{~K}$ for $24 \mathrm{~h}$.

The effect of the agitation time on adsorption was carried out by placing $500 \mathrm{mg}$ of the adsorbent ( $\gamma$ ANPs-CTAB) and $40 \mathrm{~mL}$ of a BPA solution at concentration of $20 \mathrm{mg} / \mathrm{L}$ in a bottle of $60 \mathrm{~mL}$. The whole was stirred at a speed of $600 \mathrm{rpm}$ for various contact times varying from $0 \mathrm{~min}$ up to $120 \mathrm{~min}$ at the ambient temperature.

The ratio of adsorbate (BPA) concentration to adsorbent ( $\gamma$ ANPs-CTAB) was studied by adding $40 \mathrm{~mL}$ of a BPA solution, at a concentration varying from 10 to $500 \mathrm{mg} / \mathrm{L}$, in a 
bottle of $60 \mathrm{~mL}$ containing already $500 \mathrm{mg}$ of the given $\gamma$ ANPs-CTAB under investigation. The whole was shaken with a horizontal batch shaker for $24 \mathrm{~h}$ at the ambient temperature.

The adsorption kinetics of BPA by $\gamma$ ANPs-CTAB were tested using pseudo-first-order and pseudo-second-order models. The Langmuir and Freundlich models were applied to fit the equilibrium data (Equations (4) and (5)). These isotherms are listed as below [58]:

Langmuir isotherm model

$$
\frac{\mathrm{C}_{\mathrm{e}}}{\mathrm{Q}_{\mathrm{e}}}=\frac{1}{\mathrm{~K}_{\mathrm{L}} \times \mathrm{Q}_{\mathrm{m}}}+\frac{\mathrm{C}_{\mathrm{e}}}{\mathrm{Q}_{\mathrm{m}}}
$$

where $Q_{m}\left(\frac{m g}{g}\right)$ is the Langmuir monolayer sorption capacity and $K_{L}\left(\frac{L}{m g}\right)$ is the Langmuir coefficient.

Freundlich isotherm model

$$
\ln \mathrm{Q}_{\mathrm{e}}=\ln \mathrm{k}_{\mathrm{F}}+\frac{\ln \mathrm{Ce}}{n}
$$

where $\mathrm{K}_{\mathrm{F}}(\mathrm{mg} / \mathrm{g})$ and $n$ are Freundlich constants corresponding to the adsorption capacity and the adsorption intensity, respectively.

The $R_{L}$ constant is used to predict whether an adsorption system is favorable or unfavorable. This factor is defined by Equation (6):

$$
\mathrm{R}_{\mathrm{L}}=\frac{1}{1+\mathrm{K}_{\mathrm{L}} \times \mathrm{C}_{\mathrm{i}}}
$$

$\mathrm{C}_{\mathrm{i}}$ is the initial concentration in the solution $(\mathrm{mg} / \mathrm{L})$. Isotherm adsorption is linear for $\mathrm{R}_{\mathrm{L}}=1$, unfavorable for $\mathrm{R}_{\mathrm{L}}>1$ and favorable for $0<\mathrm{R}_{\mathrm{L}}<1$.

\subsection{Statistics and Data Analysis}

The data fit of adsorption was carried out using Excel (version Microsoft Excel 2016). The average values and standard deviations analysis of the amount of CTAB (\%), effects of $\mathrm{pH}$, adsorbent dose, agitation time, and initial concentration on the adsorption of BPA by $\gamma$ ANPs-CTAB were carried out using Excel. Differences were considered significant at $p$ value $<5 \%$.

\section{Results and Discussion}

\subsection{Raw Bauxite Characterization}

The elemental composition of the BA sample was determined, and the oxide content is summarized in Table 1 . It is seen that BA contains aluminum oxide $\left(\mathrm{Al}_{2} \mathrm{O}_{3}\right)$ and silicon oxide $\left(\mathrm{SiO}_{2}\right)$ as dominant oxides. This result shows that $\mathrm{BA}$ is suitable for nano-alumina

\begin{tabular}{|c|c|c|c|c|c|c|c|c|c|c|c|c|c|c|c|}
\hline Oxides & $\mathrm{Al}_{2} \mathrm{O}_{3}$ & $\mathrm{SiO}_{2}$ & $\mathrm{Fe}_{2} \mathrm{O}_{3}$ & $\mathrm{TiO}_{2}$ & $\mathrm{P}_{2} \mathrm{O}_{5}$ & $\mathrm{CaO}$ & $\mathrm{V}_{2} \mathrm{O}_{5}$ & $\mathrm{Na}_{2} \mathrm{O}$ & $\mathrm{Cr}_{2} \mathrm{O}_{3}$ & $\mathrm{MgO}$ & $\mathrm{MnO}$ & $\mathrm{K}_{2} \mathrm{O}$ & $\mathrm{ZnO}$ & L.O.I: & Total \\
\hline wt. $\%$ & 61.66 & 25.44 & 5.71 & 4.00 & 0.15 & 0.06 & 0.06 & 0.05 & 0.04 & 0.04 & 0.03 & 0.01 & 0.006 & 2.74 & 99.94 \\
\hline
\end{tabular}
synthesis since $\mathrm{Al}_{2} \mathrm{O}_{3}$ content is high.

Table 1. Chemical composition (wt.\%) of BA sample.

\subsection{Characterizations of Synthesized Gamma-Alumina Nanoparticles ( $\gamma$ ANPs)}

The synthetized gamma-alumina nanoparticles were characterized by using ICP, BET, SEM, and AFM analyses.

Table 2 summarizes the chemical composition of the synthetized gamma-alumina nanoparticles. 
Table 2. Chemical composition of $\gamma$ ANPs.

\begin{tabular}{cccccccccc}
\hline Oxides & $\mathrm{Al}_{\mathbf{2}} \mathbf{O}_{\mathbf{3}}$ & $\mathrm{SiO}_{\mathbf{2}}$ & $\mathrm{Fe}_{\mathbf{2}} \mathbf{O}_{\mathbf{3}}$ & $\mathbf{P}_{\mathbf{2}} \mathbf{O}_{\mathbf{5}}$ & $\mathbf{V}_{\mathbf{2}} \mathbf{O}_{\mathbf{5}}$ & $\mathrm{Na}_{\mathbf{2}} \mathbf{O}$ & $\mathbf{M g O}$ & $\mathbf{K}_{\mathbf{2}} \mathbf{O}$ & $\mathrm{ZnO}$ \\
\hline wt. $\%$ & 88.00 & 5.101 & 0.100 & 0.170 & 0.020 & 0.090 & 0.020 & 0.010 & 0.005 \\
\hline
\end{tabular}

The results show that the predominant chemical compositions of $\gamma$ ANPs samples include aluminum oxide, silicon oxide, and other oxides present in trace amounts. It is then expected, in the process of functionalization by the surfactant, that aluminum and silicon oxides would be mostly coated by the CTAB. Moreover, since other oxides are present in trace amounts in the synthetized $\gamma$ ANPs, their effect, in the process of functionalization by the CTAB, can be ignored. The output values from the ICP are added together to obtain the total chemical composition. Our results are in agreement with those published in the literature $[59,60]$.

The specific surface of a powder is estimated starting from the quantity of nitrogen adsorbed in relation to its pressure to the boiling point of the Azote liquid under normal atmospheric pressure. The specific surface of $\gamma$ ANPs-CTAB was approximately $190 \mathrm{~m}^{2} / \mathrm{g}$, while the volume of the pores was approximately $0.37 \mathrm{~cm}^{3} / \mathrm{g}$. This value of specific surface is greater than $125 \mathrm{~m}^{2} / \mathrm{g}$, indicating that the synthesized $\gamma$ ANPs are very stable $[47,61]$.

Figure 1 shows the SEM image of the synthesized $\gamma$ ANPs sample after calcination. The crystals in the sample reached a porous and spongy shape, and the crystal morphology exhibited regular pores and sufficient volume for surface reactions. SEM images of synthesized nano-alumina show low bulk density and high large pores of the nanoparticles that can be explained by the evaporation of ethanol in the synthesis process [62]. The EDX spectrum in Figure 2 clearly shows the peak of $\mathrm{Al}$ and $\mathrm{O}$ as major constituents, which confirms the formation of alumina nanoparticles. Figure $3 a, b$ present the AFM surface morphology of the prepared samples. Figure 3a represented a topographic image showing three alumina nanoparticles. Figure $3 b$ indicated that the particles have almost a spherical shape. The average particle size of the prepared nano-alumina was in the nano scale catalyst.

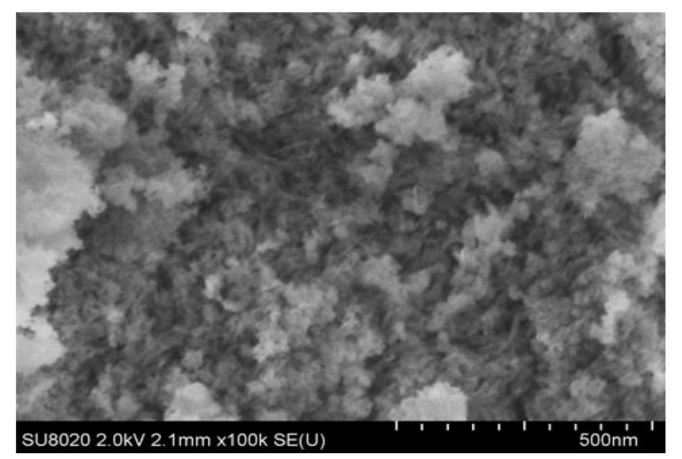

Figure 1. Scanning electron microscope (SEM) image.

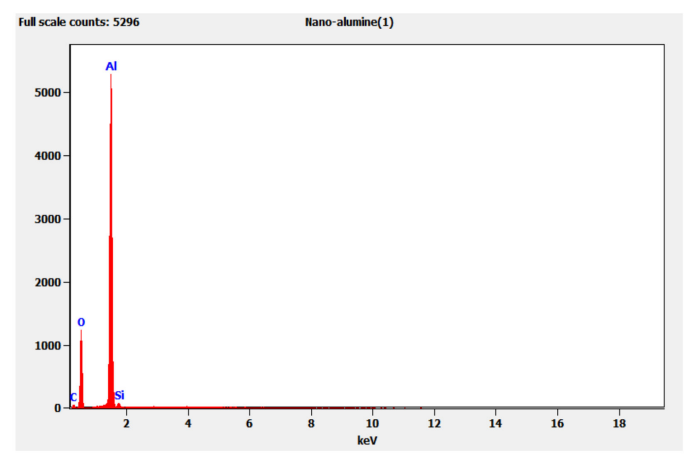

Figure 2. EDX spectrum. 


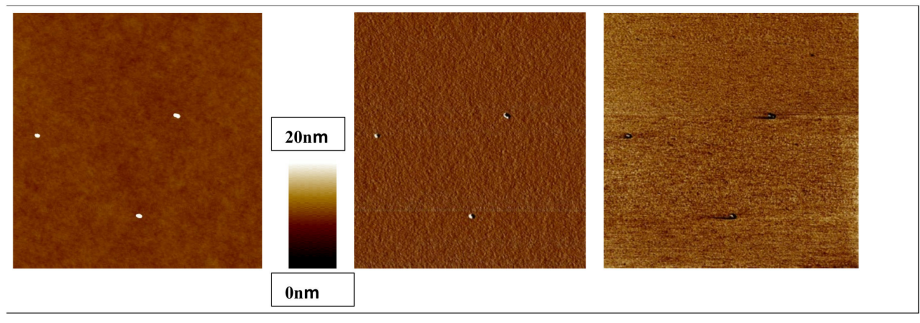

a

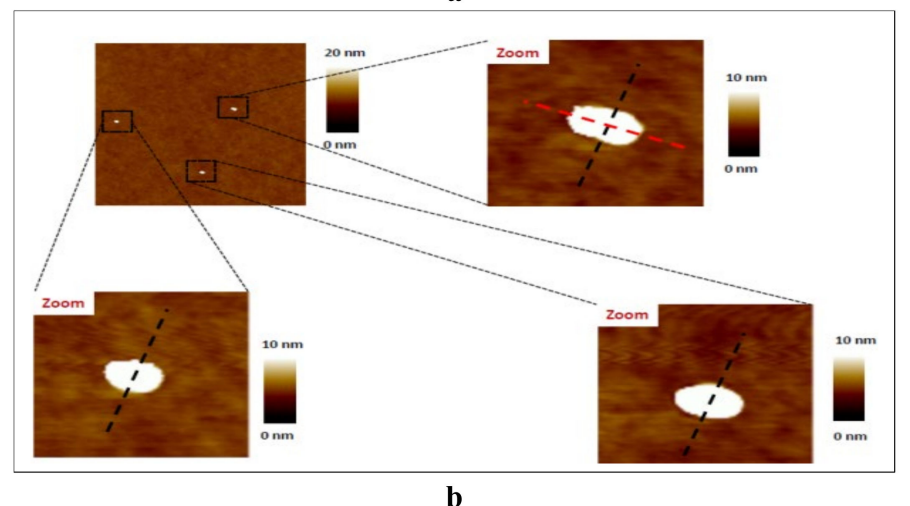

Figure 3. Images AFM: (a) topographic image showing three alumina nanoparticles; (b) form of synthesized nano-alumina particles.

The XRPD patterns of the samples before and after calcination at $900{ }^{\circ} \mathrm{C}$ are shown in Figure 4. It can be seen that the main phase found in the non-calcined samples was boehmite (JCPDS 21-1307), which is transformed into $\gamma$-alumina (JCPDS Map 29-0063) after calcination. Similar profiles of $\gamma$-alumina were obtained by other authors. We can observe three sharp peaks with high intensity at $2 \theta$ values of $37.8^{\circ}, 45.7^{\circ}$, and $66.9^{\circ}$, respectively. These peaks indicate that the $\gamma$ ANPs were synthesized with high crystallinity [63-65]. The crystallite sizes were also calculated using the Scherrer equation (Equation (7)):

$$
\mathrm{D}=\frac{\mathrm{K} \lambda}{\beta \cos \theta}
$$

where, $\mathrm{K}$ is a constant generally taken as $\sim 0.9, \lambda$ is the wavelength of the incident radiation, $\beta$ is the full width of diffraction peak at half maximum intensity (FWHM), and $\theta$ is the diffraction angle. The calculated crystallite sizes were found to be in the range of $4.1 \mathrm{~nm}$ for nano size synthesized $\gamma$-alumina [62].

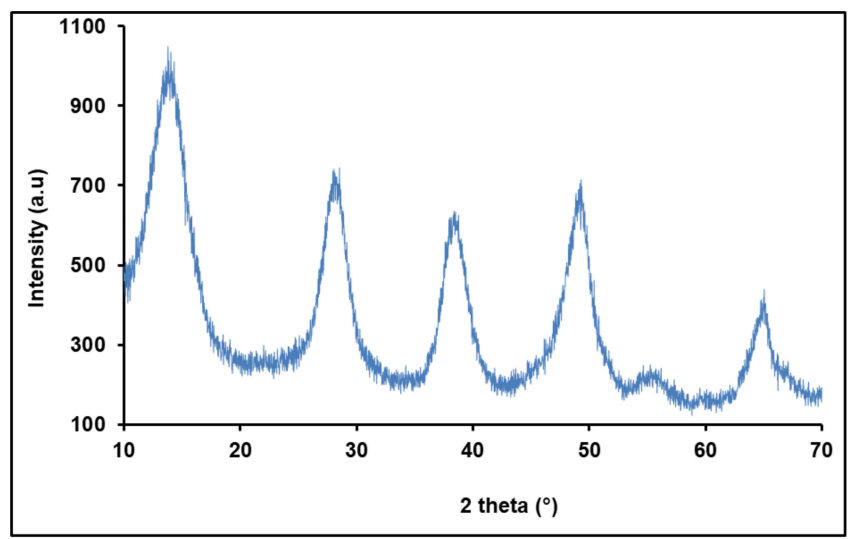

(a)

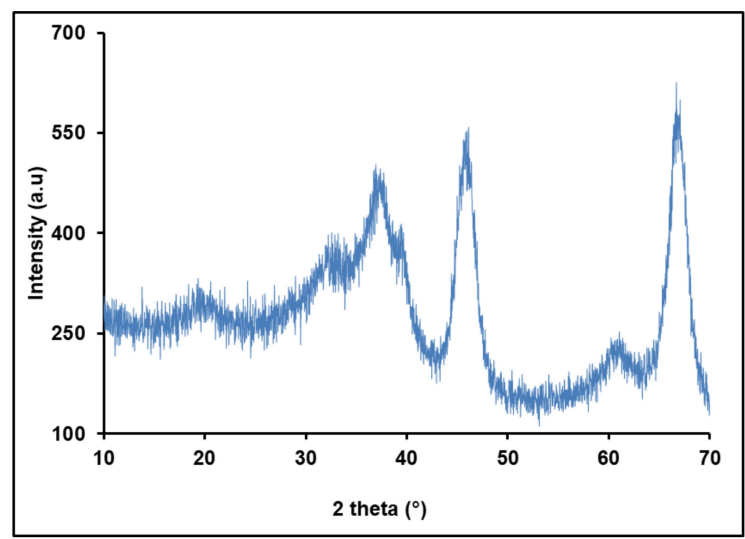

(b)

Figure 4. (a) X-ray diffraction of boehmite; (b) X-ray of $\gamma$ ANPs. 
The assessment of the surface functional groups of the adsorbent material was carried out by FTIR spectrum analysis (Figure 5). The FTIR spectrum of the synthesized $\gamma$ ANPs shows a broad band at $3457 \mathrm{~cm}^{-1}$ attributed to the stretch band of hydroxyl groups on the surface of alumina. Moreover, a weak band at $1641 \mathrm{~cm}^{-1}$ is associated with the stretching vibration band of the $\mathrm{Al}-\mathrm{OH}$ bond, and a symmetrical Al-O-Al stretching vibration band seen at $520 \mathrm{~cm}^{-1}$ corresponds to the characteristic vibration of $\mathrm{Al}_{2} \mathrm{O}_{3}$. The same observations were obtained for $\gamma$-alumina in other studies [66-69].

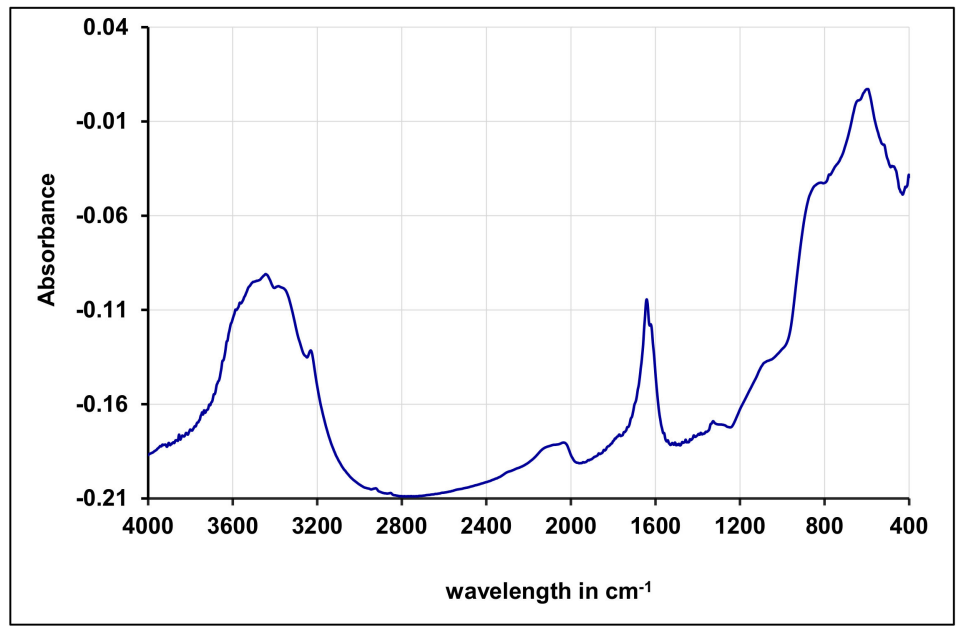

Figure 5. FTIR spectrum of nano-alumina.

The $\mathrm{pH}$ of zero-point charge $\left(\mathrm{pH}_{\mathrm{ZPC}}\right)$ of the synthesized alumina nanoparticles was determined from the point of intersection of the $\mathrm{pH}_{\text {initial }}$ vs. $\mathrm{pH}_{\text {final }}$ curve. $\mathrm{pH}_{\mathrm{ZPC}}$ indicates the electrical neutrality of the adsorbent at certain $\mathrm{pH}$ values when the concentration of positively charged surface groups is the same as that of negatively charged ones. The $\mathrm{pH}_{\mathrm{ZPC}}$ of alumina nanoparticles was found to be eight (Figure 6), which is close to that reported by Li et al. (2011) [70]. The pHzpc for the $\gamma$-alumina obtained is in agreement with other studies in which the pHzpc was 7.9 [71] and 8 [66]. At pH values below pHzpc, the surface of the adsorbent is positively charged; at values greater than $\mathrm{pHzpc}$, the surface of the adsorbent is negatively charged. Thus, at $\mathrm{pH}$ values below eight, the synthesized $\gamma$ ANPs are positively charged, and at values above $\mathrm{pH} 8$ they are negatively charged $[56,57]$.

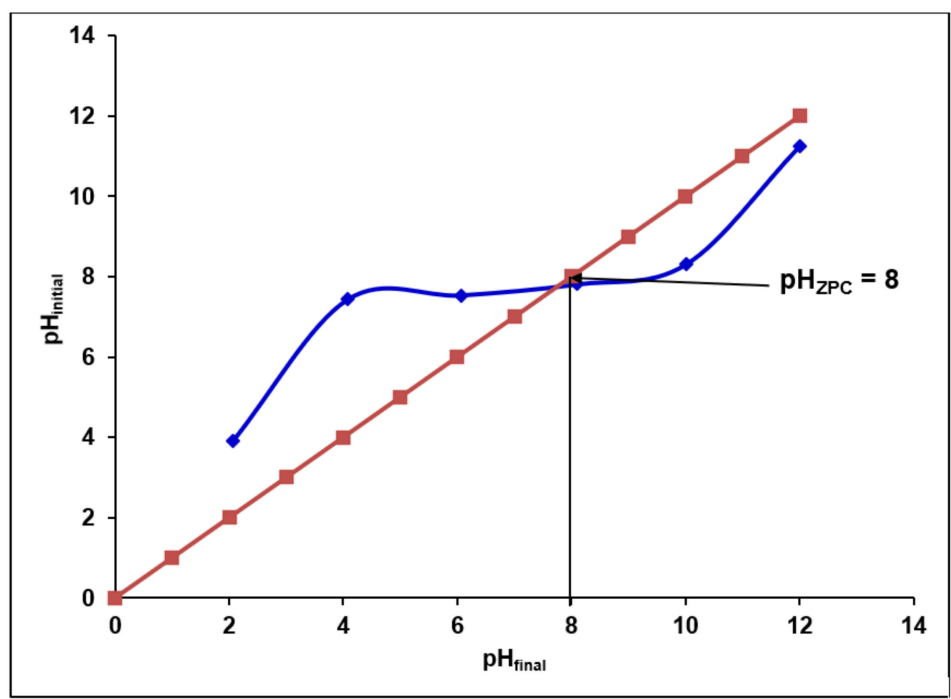

Figure 6. Zero-point charge $\left(\mathrm{pH}_{\mathrm{ZPC}}\right)$ of synthesis nano-alumina. 


\subsection{Effect of Surfactant (CTAB) Loading Levels}

Positively charged surfactants, such as $\mathrm{CTAB}$, can strongly adsorb on negatively charged surfaces of $\gamma$-ANPs in basic solutions. A concentration of CTAB, below its critical micellar concentration $\left(\mathrm{CMC}, 1 \times 10^{-3} \mathrm{~mol} \cdot \mathrm{L}^{-1}\right)$, was used. Above this concentration, the excess of CTAB would form micelles in the aqueous solution, which are not adsorbed on $\gamma$-ANPs surfaces. Therefore, the influence of various percentages of CTAB in $\gamma$ ANPs-CTAB on the adsorption of $20 \mathrm{mg} / \mathrm{L}$ BPA through the $\gamma$ ANPs-CTAB adsorbent was investigated. The results showed that maximum adsorption was obtained when a mixture containing $35 \%$ of CTAB was used (Figure 7). Thus, this percentage was selected as the optimum amount of $\mathrm{CTAB}$ for further studies.

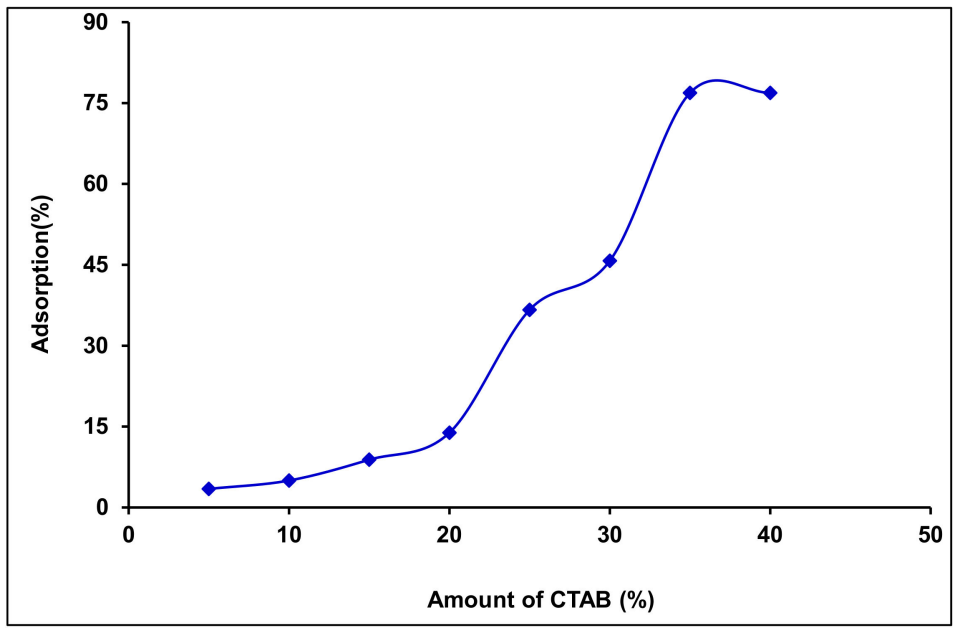

Figure 7. Effect of amount of CTAB (\%) on BPA adsorption.

\subsection{Batch Investigations of BPA Adsorption onto $\gamma$ ANPs-CTAB \\ 3.4.1. Effect of Initial $\mathrm{pH}$}

The adsorbent $\gamma$ ANPs-CTAB used in this study are composed of nanoparticles with a size around $4.1 \mathrm{~nm}$ and CTAB composition estimated at $35 \%$. The $\mathrm{pH}$ of the suspension has a great influence on the optimum condition for the adsorption process, and this was investigated at $\mathrm{pH}$ values ranging from 2 to 12 . The results in Figure 8 show that the $\gamma$ ANPsCTAB have a higher adsorption capacity for BPA when the $\mathrm{pH}$ values are ranged from 4 to $10\left(1.39\right.$ to $\left.1.41 \mathrm{mg} \cdot \mathrm{g}^{-1}\right)$, with a slight decrease in adsorption capacity $\left(1.02 \mathrm{mg} \cdot \mathrm{g}^{-1}\right)$ at $\mathrm{pH}$ 10. For $\mathrm{pH}$ values less than four, the BPA removal from the aqueous solution was lower and this means that in an acidic medium the uptake of BPA molecules by the $\gamma$ ANPs-CTAB is highly influenced. At $\mathrm{pH}$ values higher than 10, a decrease in the adsorbent capacity was observed. According to Pham et al. 2013, when the $\mathrm{pH}$ value is less than four $(\mathrm{pH}<4)$, the $\gamma$ ANPs are dissolved and this changes the characteristics of those materials [72], which induces the decrease of $\gamma$ ANPs-CTAB efficiency toward BPA adsorption. From $\mathrm{pH} 4$ to 9.6, the adsorption mechanism may involve a portioning process into the organic solventlike created by the $\mathrm{C}-16$ chain of CTAB (hydrophobic interaction). Above $\mathrm{pH}$ 9.6, BPA becomes an anionic species, and the adsorption is governed by electrostatic interaction. Hence, the adsorption of BPA onto $\gamma$ ANPs-CTAB at $\mathrm{pH} 10$ was mainly due to electrostatic interactions between the BPA, negatively charged $\left(\mathrm{O}^{-}\right)$, and the positive cationic micelle of the adsorbent [44]. The above results are similar to those reported by Dovi et al. on BPA removal by using CTAB functionalized walnut shell [73]. In fact, the authors reported that the surface of the modified adsorbent became both positively charged and non-polar, which made it more suitable for the uptake of neutral BPA as well as BPA anion. Based on the above result, the operating $\mathrm{pH}$ for the subsequent experiments was fixed at a $\mathrm{pH}$ value of 10. At a higher $\mathrm{pH}(\mathrm{pH}>10)$, the medium becomes very rich in hydroxyl ions $\left(\mathrm{OH}^{-}\right)$. Since the surface of the adsorbent is positively charged, the $\mathrm{OH}^{-}$ions would neutralize the 
positive charges of the $\mathrm{CTAB}$. As a result, there is a decrease in the interaction between the positive adsorbent surface and the BPA ions [73].

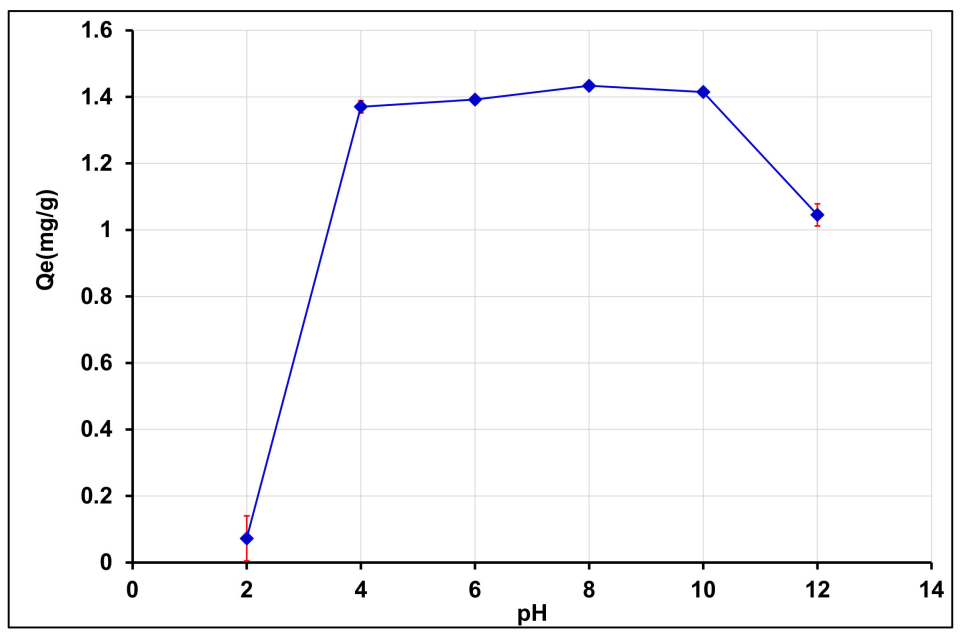

Figure 8. Effect of $\mathrm{pH}$ on the adsorption of BPA by $\gamma$ ANPs-CTAB.

\subsubsection{Effect of Adsorbent Dose}

The effect of the adsorbent dose is shown in Figure 9. It was observed that the removal efficiency increased from $47.08 \pm 5.80 \%$ to $91.80 \pm 0.21 \%$ with the increased adsorbent dose. This can be attributed to the increase in the adsorbent specific surface area and availability of more adsorption sites [74]. Consequently, the adsorbent dose was maintained at $0.5 \mathrm{~g}$ in all the subsequent experiments, which was considered to be sufficient for the removal of BPA. From Figure 9, we see that the adsorbed quantity increases progressively with the increase in the mass of the adsorbent used, which means that increasing the adsorbent dose increases the number of sites available for the binding of bisphenol-A [75].

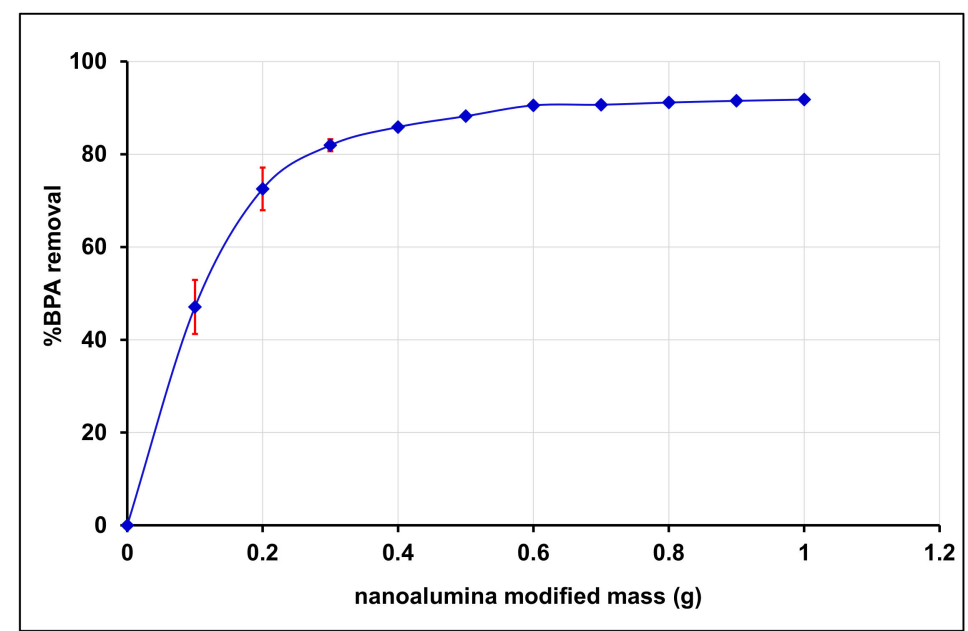

Figure 9. Effect of the adsorbent dose on the adsorption of BPA.

3.4.3. Effect of the Agitation Time on BPA Adsorption and Kinetics Effect of the Agitation Time on BPA Adsorption

Adsorption was studied as a function of the agitation time to determine the amount of BPA adsorbed at different times (Figure 10). Equilibrium time is one of the most economically important factors for polluted water treatment systems [76]. The amount of BPA adsorbed for each interval of time was calculated and the obtained results allowed for the determination of the minimal agitation time required to reach the equilibrium and the evaluation of the pseudo-first and pseudo-second-order kinetic models. Analysis 
of Figure 10 shows that the rate of adsorption of BPA by $\gamma$ ANPs-CTAB changes rapidly during the first $20 \mathrm{~min}$ (reaching $89 \%$ of BPA adsorption), then decreases over time until it reaches saturation after $1 \mathrm{~h}$. The rapid adsorption kinetics recorded during the first few minutes can be explained by the availability of a large number of active sites on the surface of the material at the beginning of the adsorption process.

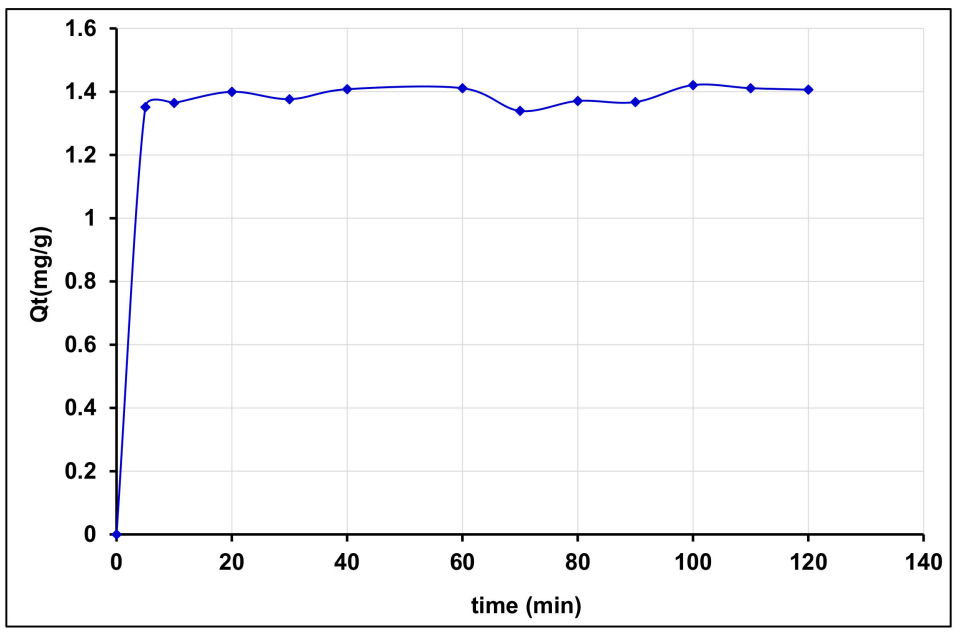

Figure 10. Effect of agitation time of BPA adsorption on the $\gamma$ ANPs-CTAB.

\section{Adsorption Kinetics}

The kinetic results of BPA adsorption on $\gamma$ ANPs-CTAB are indicated in Figure 11a,b. The kinetic results were fitted using pseudo-first-order and pseudo-second-order models. Figure 11a corresponds to the pseudo-first kinetic model and Figure $11 \mathrm{~b}$ corresponds to the pseudo-second kinetic model. The obtained kinetic constants and determination coefficients of BPA removal using the $\gamma$ ANPs-CTAB at $500 \mathrm{mg} \cdot \mathrm{L}^{-1}$ as the adsorbent dose are summarized in Table 3. It is shown that the pseudo-second-order kinetic model fits better the experimental results than the pseudo-first-order kinetic model in this work (Figure 11a,b). This observation is confirmed by the high determination coefficients of the pseudo-second-order kinetic model $\left(\mathrm{R}^{2}>0.99\right)$ compared to those of the pseudofirst-order kinetic model $\left(\mathrm{R}^{2}<0.85\right)$ (Table 3$)$. The pseudo-second-order kinetic model suggests that the chemisorption could be considered as a limiting step during the adsorption process $[10,25]$. This finding resembles those reported for BPA adsorption on the following adsorbents: graphene [77], CTAB modified palygorskite [78], surfactantmodified zeolite [79], and organo-montmorillonites [10,24,25,80,81]. For the most part, the pseudo-second-order better interprets the kinetic experimental data of the BPA adsorption on several adsorbents [10,25,77-80,82,83]. In a previous study, Vithanage et al. (2016) reported that the kinetic order depends on the initial concentrations. The authors indicated that the pseudo-second-order kinetic model could better fit the experimental data when the pollutant molecules were less abundant (low initial concentration) compared to the available adsorption sites [84]. The present results on BPA adsorption kinetics could be explained by the BPA concentration at the $\gamma$ ANPs $-C T A B / B P A$ solution interface. 


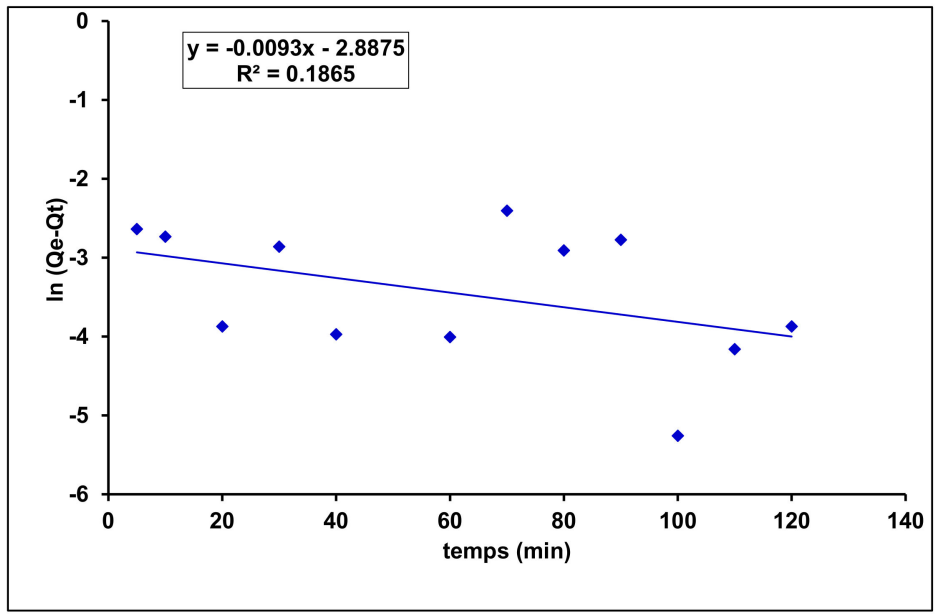

(a)

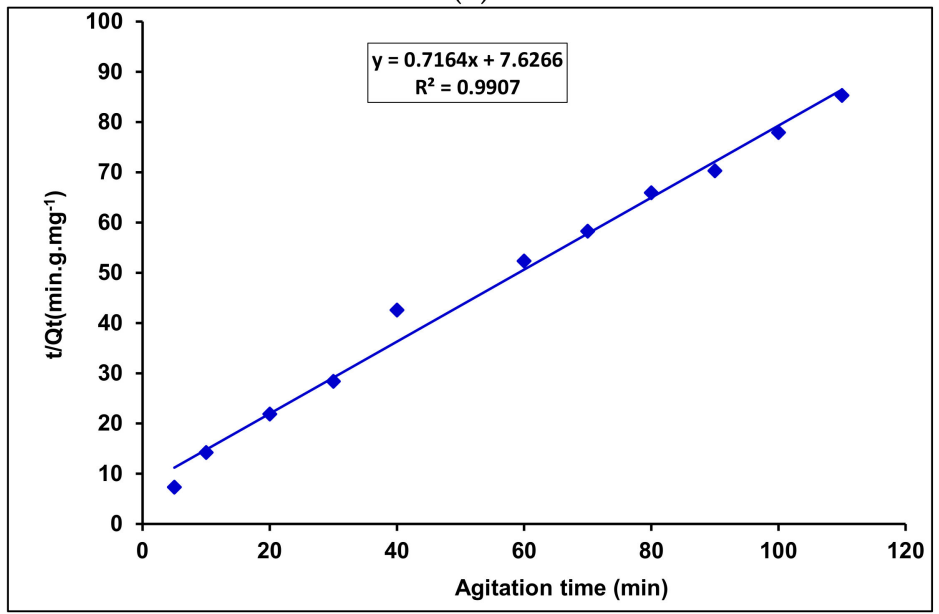

(b)

Figure 11. (a) Pseudo-first model of BPA adsorption on the $\gamma$ ANPs-CTAB; (b) pseudo-second model of BPA adsorption on the $\gamma$ ANPs-CTAB.

Table 3. Kinetic constants of BPA removal on $\gamma$ ANPs-CTAB.

\begin{tabular}{|c|c|c|c|c|c|c|}
\hline \multirow{2}{*}{ Sorbent } & \multicolumn{3}{|c|}{ Pseudo-First-Order } & \multicolumn{3}{|c|}{ Pseudo-Second-Order } \\
\hline & $K_{1}\left(\min ^{-1}\right)$ & $\mathrm{Qe}_{1}(\mathrm{mg} / \mathrm{g})$ & $\mathbf{R}^{2}$ & $K_{2}\left(\min ^{-1}\right)$ & $\mathrm{Qe}_{2}(\mathrm{~g} / \mathrm{mg} \cdot \mathrm{min})$ & $\mathbf{R}^{2}$ \\
\hline$\gamma$ ANPs-CTAB & 0.0093 & 0.0557 & 0.1865 & 0.0673 & 1.3959 & 0.9907 \\
\hline
\end{tabular}

3.4.4. Effect of Initial Concentration of BPA Solution and Isotherms Effect of Initial Concentration of BPA Solution

Figure 12 shows the quantities of BPA removed at different initial concentrations and for $24 \mathrm{~h}$ as the agitation time. These results indicate that the amount of BPA removed from water increases quickly up to $100 \mathrm{mg} / \mathrm{L}$ as the initial concentration. As shown in Figure 12, the equilibrium adsorption capacity of BPA on $\gamma$ ANPs-CTAB increases with increasing initial concentration, until the saturation of available reactive sites [83]. The curves of the BPA quantity removed are almost relatively linear up to $100 \mathrm{mg} / \mathrm{L}$ of BPA and become parabolic after that value. Thus, the BPA initial concentration affects the adsorption of BPA on the $\gamma$ ANPs-CTAB. In fact, before $100 \mathrm{mg} / \mathrm{L}$ as the BPA initial concentration, the active sites of $\gamma$ ANPs-CTAB are more available and this induces better adsorption. However, the gradual saturation of the active sites induces a less efficient adsorption after $100 \mathrm{mg} / \mathrm{L}$. In this work, when the initial BPA concentration increases from 10 to $500 \mathrm{mg} / \mathrm{L}$, the values of adsorbed BPA (Qe) for $500 \mathrm{mg}$ of $\gamma$ ANPs-CTAB increase from $0.667 \pm 0.002$ 
to $19.54 \pm 0.159 \mathrm{mg} / \mathrm{g}$. This result is similar to those reported by Adeyemo et al. (2017), Gorzin and Abadi (2018), and Rathnayake et al. (2016) [25,85,86].

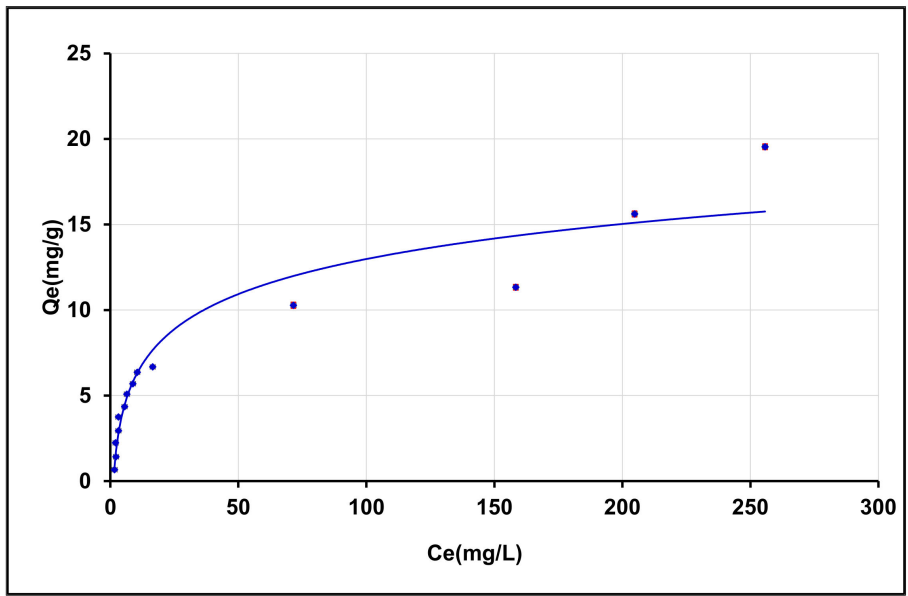

Figure 12. Initial concentration effect on the BPA adsorption by $\gamma$ ANPs-CTAB.

Adsorption Isotherms

Adsorption isotherms describe the relationship between the amount of adsorbate adsorbed by the adsorbent $\left(\mathrm{Q}_{\mathrm{e}}\right)$ and the concentration of adsorbate remaining in the solution after the system reaches the equilibrium $\left(\mathrm{C}_{\mathrm{e}}\right)$ at a constant temperature. In this study, the Langmuir and Freundlich models were applied to fit the equilibrium data. The Langmuir and Freundlich models are presented in Figure 13.

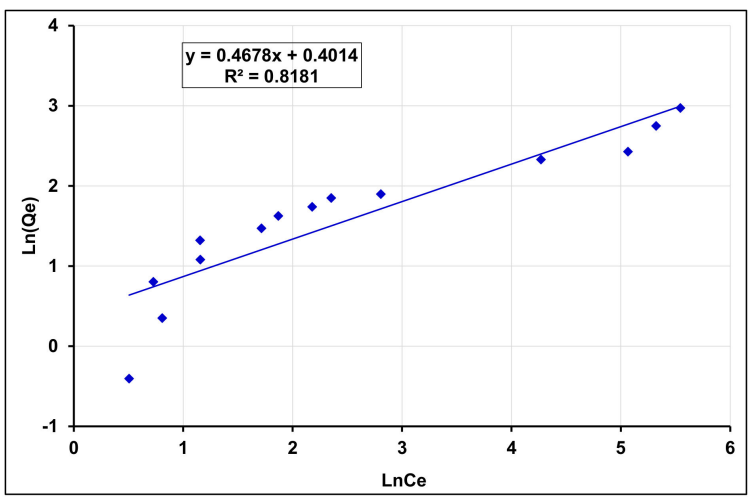

(a)

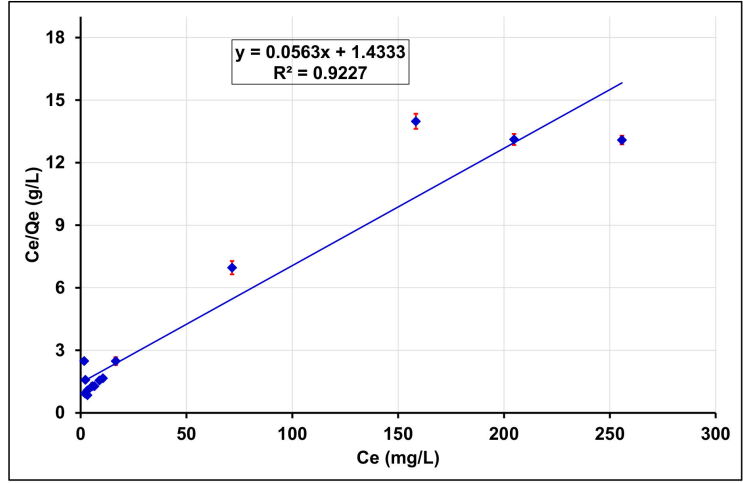

(b)

Figure 13. (a) Freundlich isotherm of BPA adsorption on the $\gamma$ ANPs-CTAB; (b) Langmuir isotherm of BPA adsorption on the $\gamma$ ANPs-CTAB.

Figure 13a corresponds to the Freundlich isotherm and Figure 13b represents the 
Langmuir isotherm. Considering these figures, the isotherm parameters of BPA adsorption were evaluated at room temperature and summarized in Table 4 . According to Table 4, the obtained determination coefficient $\left(\mathrm{R}^{2}\right)$ values indicate that the BPA adsorption data fit better the Langmuir isotherm $\left(0.89<\mathrm{R}^{2}<0.99\right)$ than the Freundlich isotherm $\left(0.8<\mathrm{R}^{2}<0.95\right)$. These results are similar to those reported previously on BPA removal using organically modified montmorillonite [24,80] and amphoteric modified vermiculite [87]. It is also seen that all $n$ values in the Freundlich isotherm are higher than one (Table 4), implying $1 / n<1$, which sustains that the Langmuir isotherm describes better the adsorption process.

Table 4. Isotherm parameters of BPA adsorption on the $\gamma$ ANPs-CTAB.

\begin{tabular}{ccccccc}
\hline \multirow{2}{*}{ Sorbent } & \multicolumn{3}{c}{ Langmuir } & \multicolumn{3}{c}{ Freundlich } \\
\cline { 2 - 7 } & $\mathbf{K}_{\mathbf{L}}(\mathbf{L} / \mathbf{m g})$ & $\mathbf{Q m}(\mathbf{m g} / \mathbf{g})$ & $\mathbf{R}^{\mathbf{2}}$ & $\mathbf{K}_{\mathbf{F}}(\mathbf{L} / \mathbf{g})$ & $\boldsymbol{n}$ & $\mathbf{R}^{\mathbf{2}}$ \\
\hline$\gamma$ ANPs-CTAB & 0.0403 & 17.4825 & 0.9201 & 1.5324 & 2.1786 & 0.8077 \\
\hline
\end{tabular}

Table 5 shows that all the $\mathrm{R}_{\mathrm{L}}$ values are between zero and one, indicating that the adsorption of BPA on the prepared $\gamma$ ANPs-CTAB was favorable at the conditions being studied [88]. Moreover, when the initial concentration increases from 10 to $500 \mathrm{mg} / \mathrm{L}$, the $R_{L}$ values decrease from 0.71 to 0.047 for the $\gamma$ ANPs-CTAB, suggesting a more favorable adsorption process at higher concentrations [88].

Table 5. Equilibrium parameter $\left(\mathrm{R}_{\mathrm{L}}\right)$ on the BPA adsorption.

\begin{tabular}{|c|c|c|c|c|c|c|c|c|c|c|c|c|c|}
\hline$[B P A] \mathrm{mg} / \mathrm{L}$ & 10 & 20 & 30 & 40 & 60 & 70 & 80 & 90 & 100 & 200 & 300 & 400 & 500 \\
\hline $\mathrm{R}_{\mathrm{L}}$ & 0.712 & 0.553 & 0.452 & 0.382 & 0.292 & 0.261 & 0.236 & 0.216 & 0.198 & 0.110 & 0.076 & 0.058 & 0.047 \\
\hline
\end{tabular}

\subsubsection{Investigations on $\gamma$ ANPs-CTAB before and after BPA Adsorption FTIR Investigations}

The adsorption capacity of an adsorbent is dependent on the chemical reactivity of the functional groups at the adsorbent surface [89]. FTIR is a powerful tool to evaluate the change in functional groups after adsorption [90]. Figure 14a,b show the ATR mode infrared spectra of $\gamma$ ANPs-CTAB before and after BPA adsorption, respectively, in the wavenumber range $1000-4000 \mathrm{~cm}^{-1}$. Figure 14a shows that the ATR mode infrared spectra of $\gamma$ ANPs after $\mathrm{CTAB}$ adsorption are similar to the raw one (Figure 5). We can see that the strong band of stretching vibration of $-\mathrm{OH}$ appearing in the wavelength of about $3658.96 \mathrm{~cm}^{-1}$ for $\gamma$ ANPs-CTAB (Figure 14a) is similar to the FTIR spectrum of synthesized $\gamma$ ANPs (Figure 5). Moreover, a weak band at $1641 \mathrm{~cm}^{-1}$ is associated with the stretching vibration band of the Al-OH bond of the $\gamma$ ANPs. The appearance of a significant $\mathrm{C}-\mathrm{H}$ stretching vibration band between 3000 and $2800 \mathrm{~cm}^{-1}$ indicates the alkyl chain of the template molecule CTAB. The CTAB functionalized $\gamma$ ANPs generate new significant bands observed near 2800 and $2900 \mathrm{~cm}^{-1}$ due to the symmetric and asymmetric stretching vibration band of the $\mathrm{CH}_{2}$ group. This result indicates that CTAB is deposited on the surface of the $\gamma$ ANPs and induces an increase of the active site numbers.

The infrared spectrum bands of $\gamma$ ANPs-CTAB after BPA adsorption were investigated. The presence of BPA on $\gamma$ ANPs-CTAB was confirmed by the infrared spectroscopy. There were significant changes on the FTIR spectrum of $\gamma$ ANPs-CTAB after interaction with BPA. When we compare the FTIR spectra of $\gamma$ ANPs-CTAB before and after BPA adsorption (Figure 14a,b), it is observed that the intensities of the -OH stretching mode seen at 3651, 3643 , and $3480 \mathrm{~cm}^{-1}$ decrease after BPA adsorption. The intensities of the bands attributed to the $\mathrm{CH}_{2}$ stretching vibration seen at 2925 and $2857 \mathrm{~cm}^{-1}$ decrease after BPA adsorption on $\gamma$ ANPs-CTAB, indicating that these groups participate in the adsorption process. A new band appearing at $2965 \mathrm{~cm}^{-1}$ is attributed to the methyl groups of BPA molecules. 


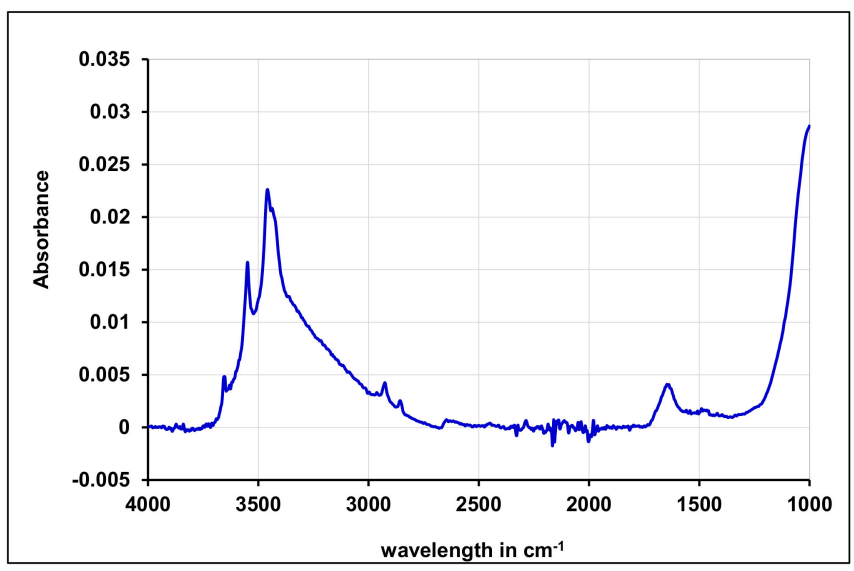

(a)

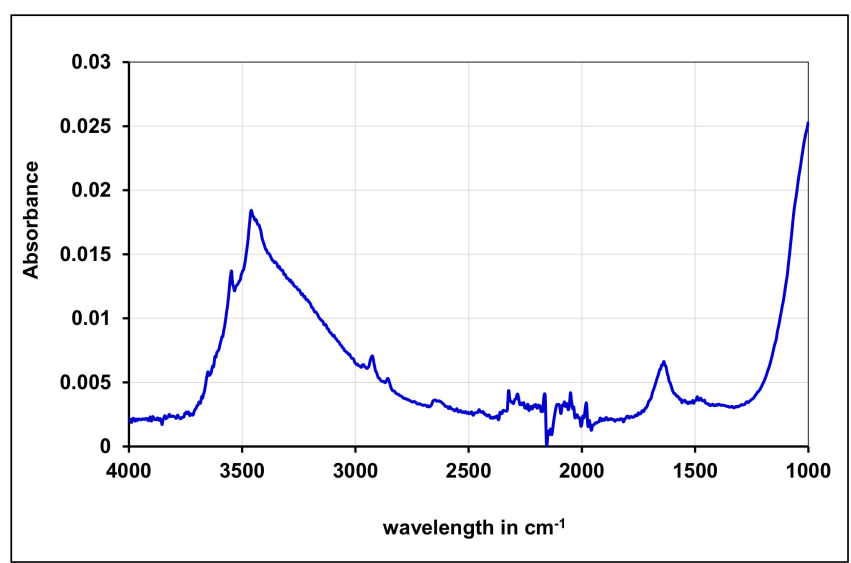

(b)

Figure 14. FTIR spectrum of (a) $\gamma$ ANPs-CTAB and (b) $\gamma$ ANP-CTAB after BPA adsorption.

\section{SEM Investigations}

The morphology of the $\gamma$ ANPs-CTAB was investigated using SEM. The SEM images recorded at different magnifications show that CTAB is uniformly coated at the surface of the $\gamma$ ANPs. This induces the appearance of active sites on the surface of the $\gamma$ ANPsCTAB. Figure 15 shows the SEM micrograph for $\gamma$ ANPs-CTAB powders before and after adsorption of BPA. The $\gamma$ ANPs-CTAB image before BPA adsorption (Figure 15a) indicates a low agglomeration of particles with uniform sizes and a spongy structure. Figure $15 b$ shows that, after BPA adsorption, a high agglomeration was observed.

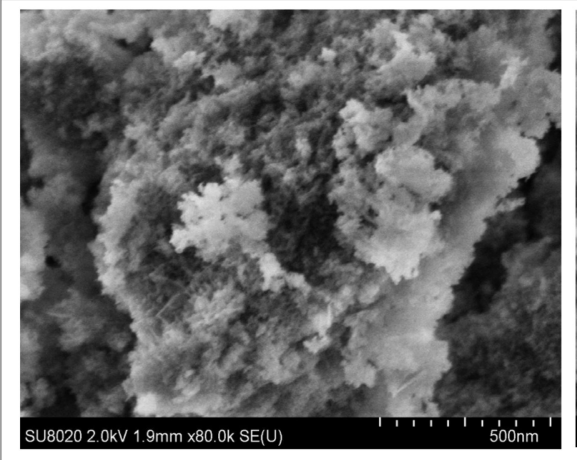

(a)

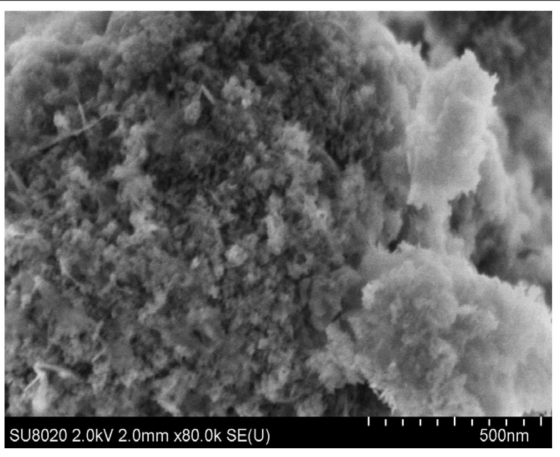

(b)

Figure 15. SEM image of (a) $\gamma$ ANPs-CTAB and (b) $\gamma$ ANPs-CTAB after BPA adsorption.

XRPD Investigations

To understand the nature of the $\gamma \mathrm{ANPs}-\mathrm{CTAB}$ and to evaluate the changes after BPA adsorption, XRPD investigation was carried out. The X-ray patterns of $\gamma$ ANPs-CTAB (Figure 16a,b) show the crystalline nature of $\gamma$ ANPs-CTAB before and after BPA adsorption and the associated peaks that are typically attributed to $\gamma$ ANPs were also observed, as in Figure $4 \mathrm{~b}$. The extent of the crystallization changes after surface modification indicates successful dispersion of CTAB on the $\gamma$ ANPs (Figure 16a). In addition, the intensities of the peaks observed at $18.8,20.29$, and $40.59^{\circ}$ decrease slightly after the adsorption of BPA (Figure 16b). 


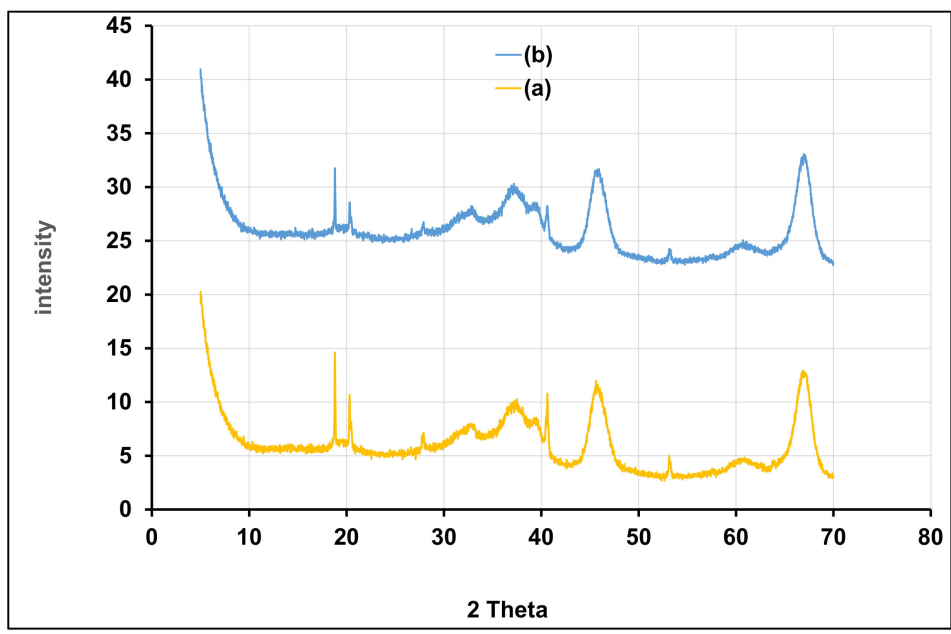

Figure 16. X-ray diffraction of (a) $\gamma$ ANPs-CTAB and (b) $\gamma$ ANPs-CTAB after BPA adsorption.

\section{Conclusions}

In this study, $\gamma$ ANPs with a crystallite size of $4.1 \mathrm{~nm}$ were synthesized from boehmite derived from natural local bauxite sources by calcination. This work also showed that the modification of the synthesized $\gamma$-alumina using CTAB leads to a better adsorption performance of BPA with a high adsorption rate. Kinetic and isotherm models were tested. We found a better fit for the kinetic results was the pseudo-second-order, and the isotherm model is described by the Langmuir isotherm. In this case, the adsorption process may be related to hydrophobic interaction at $\mathrm{pH}$ values ranging from 4 to 9.6 , and electrostatic interaction at a $\mathrm{pH}$ value of 10 . At $\mathrm{pH}$ values greater than 10, the adsorbent surface being neutralized by hydroxyl ions, the interaction between the adsorbent surface and the BPA ions weakens and this leads to the decrease of the adsorption.

Author Contributions: Conceptualization, O.R.K., I.G., C.B., and B.G.; methodology, O.R.K., I.G., C.B., and B.G.; investigation, O.R.K. and I.G.; writing—original draft preparation, O.R.K.; writingreview and editing, O.R.K., I.G., C.B., and B.G.; supervision, C.B. and B.G.; funding acquisition, B.G. All authors have read and agreed to the published version of the manuscript.

Funding: This work was supported by the International Science Programme [ISP], Uppsala, Sweden.

Institutional Review Board Statement: Not applicable.

Informed Consent Statement: Not applicable.

Data Availability Statement: Not applicable.

Acknowledgments: This work was supported by the International Science Programme [ISP], Uppsala, Sweden. Their financial support is gratefully acknowledged.

Conflicts of Interest: Authors have declared that no competing interests exist.

\section{References}

1. Arnold, S.M.; Clark, K.E.; Staples, C.A.; Klecka, G.M.; Dimond, S.S.; Caspers, N.; Hentges, S.G. Relevance of drinking water as a source of human exposure to bisphenol A. J. Expo. Sci. Environ. Epidemiol. 2012, 23, 137-144. [CrossRef]

2. Saal, F.S.V.; Welshons, W.V. Large effects from small exposures. II. The importance of positive controls in low-dose research on bisphenol A. Environ. Res. 2006, 100, 50-76. [CrossRef]

3. Staples, C.A.; Dome, P.B.; Klecka, G.M.; Oblock, S.T.; Harris, L.R. A review of the environmental fate, effects, and exposures of bisphenol A. Chemosphere 1998, 36, 2149-2173. [CrossRef]

4. Chevalier, N. Les perturbateurs endocriniens: De nouveaux acteurs dans l'épidémie d'obésité et de diabète de type 2? Corresp. Métab. Horm. Diabètes Nutr. 2014, 100, 248-252.

5. ANSES. Evaluation des Risques du Bisphénol A (BPA) pour la Santé Humaine; Tome 1; Agence Nationale de Sécurité Sanitaire de l'Alimentation, de l'Environnement et du Travail (ANSES): Paris, France, 2013. 
6. $\quad$ Pop, C.-E.; Draga, S.; Măciucă, R.; Niță, R.; Crăciun, N.; Wolff, R. Bisphenol A Effects in Aqueous Environment on Lemna minor. Processes 2021, 9, 1512. [CrossRef]

7. Wang, Z.-M.; Ooga, H.; Hirotsu, T.; Wang, W.; Wu, Q.Y.; Hu, H.-Y. Matrix-enhanced adsorption removal of trace BPA by controlling the interlayer hydrophobic environment of montmorillonite. Appl. Clay Sci. 2015, 104, 81-87. [CrossRef]

8. United States Environmental Protection Agency. Special Report on Environmental Endocrine Disruption: An Effects Assessment and Analysis; USEPA: Washington, DC, USA, 1997.

9. Bautista-Toledo, I.; Ferro-Garcia, M.; Rivera-Utrilla, J.; Moreno-Castilla, C.; Vegas Fernández, F. Bisphenol A removal from water by activated carbon. Effects of carbon characteristics and solution chemistry. Environ. Sci. Technol. 2005, 39, 6246-6250. [CrossRef]

10. Park, Y.; Sun, Z.; Ayoko, G.A.; Frost, R.L. Bisphenol A sorption by organo-montmorillonite: Implications for the removal of organic contaminants from water. Chemosphere 2014, 107, 249-256. [CrossRef]

11. Rivas, F.J.; Encinas, Á.; Acedo, B.; Beltran, F.J. Mineralization of bisphenol A by advanced oxidation processes. J. Chem. Technol. Biotechnol. 2009, 84, 589-594. [CrossRef]

12. Yüksel, S.; Kabay, N.; Yüksel, M. Removal of bisphenol A (BPA) from water by various nanofiltration (NF) and reverse osmosis (RO) membranes. J. Hazard. Mater. 2013, 263, 307-310. [CrossRef]

13. Cui, Y.-H.; Li, X.-Y.; Chen, G. Electrochemical degradation of bisphenol A on different anodes. Water Res. 2009, 43, 1968-1976. [CrossRef]

14. Murugananthan, M.; Yoshihara, S.; Rakuma, T.; Shirakashi, T. Mineralization of bisphenol A (BPA) by anodic oxidation with boron-doped diamond (BDD) electrode. J. Hazard. Mater. 2008, 154, 213-220. [CrossRef] [PubMed]

15. Umar, M.; Roddick, F.; Fan, L.; Aziz, H.A. Application of ozone for the removal of bisphenol A from water and wastewater-A review. Chemosphere 2013, 90, 2197-2207. [CrossRef] [PubMed]

16. Yang, X.; Tian, P.-F.; Zhang, C.; Deng, Y.-Q.; Xu, J.; Gong, J.; Han, Y.-F. Au/carbon as Fenton-like catalysts for the oxidative degradation of bisphenol A. Appl. Catal. B Environ. 2013, 134-135, 145-152. [CrossRef]

17. Wang, C.; Zhang, H.; Li, F.; Zhu, L. Degradation and mineralization of bisphenol A by mesoporous $\mathrm{Bi}_{2} \mathrm{WO}_{6}$ under simulated solar light irradiation. Environ. Sci. Technol. 2010, 44, 6843-6848. [CrossRef]

18. Torres, R.A.; Pétrier, C.; Combet, E.; Moulet, F.; Pulgarin, C. Bisphenol A mineralization by integrated ultrasound-UV-iron (II) treatment. Environ. Sci. Technol. 2007, 41, 297-302. [CrossRef]

19. Cajthaml, T.; Krësinová, Z.; Svobodová, K.; Möder, M. Biodegradation of endocrine-disrupting compounds and suppression of estrogenic activity by ligninolytic fungi. Chemosphere 2009, 75, 745-750. [CrossRef] [PubMed]

20. Tsai, W.T.; Lai, C.-W.; Su, T.-Y. Adsorption of bisphenol-A from aqueous solution onto minerals and carbon adsorbents. J. Hazard. Mater. 2006, 134, 169-175. [CrossRef] [PubMed]

21. Tsai, W.T.; Hsu, H.C.; Su, T.Y.; Lin, K.Y.; Lin, C.M. Adsorption characteristics of bisphenol-A in aqueous solutions onto hydrophobic zeolitea. J. Colloid Interface Sci. 2006, 299, 513-519. [CrossRef] [PubMed]

22. Li, J.; Zhan, Y.; Lin, J.; Jiang, A.; Xi, W. Removal of bisphenol A from aqueous solution using cetylpyridinium bromide (CPB)modified natural zeolites as adsorbents. Environ. Earth Sci. 2014, 72, 3969-3980. [CrossRef]

23. Dong, Y.; Wu, D.; Chen, X.; Lin, Y. Adsorption of bisphenol A from water by surfactant-modified zeolite. J. Colloid Interface Sci. 2010, 348, 585-590. [CrossRef] [PubMed]

24. Zheng, S.; Sun, Z.; Park, Y.; Ayoko, G.A.; Frost, R.L. Removal of bisphenol A from wastewater by Ca-montmorillonite modified with selected surfactants. Chem. Eng. J. 2013, 234, 416-422. [CrossRef]

25. Rathnayake, S.I.; Xi, Y.; Frost, R.L.; Ayoko, G.A. Environmental applications of inorganic-organic clays for recalcitrant organic pollutants removal: Bisphenol A. J. Colloid Interface Sci. 2016, 470, 183-195. [CrossRef]

26. Garikoé, I.; Sorgho, B.; Yaméogo, A.; Guel, B.; Andala, D. Removal of bisphenol A by adsorption on organically modified clays from Burkina Faso. Bioremediat. J. 2021, 25, 22-47. [CrossRef]

27. Kimura, Y.; Yamamoto, M.; Shimazaki, R.; Kashiwada, A.; Matsuda, K.; Yamada, K. Use of Chitosan for Removal of Bisphenol A from Aqueous Solutions Through Quinone Oxidation by Polyphenol Oxidase. J. Appl. Polym. Sci. 2012, 124, 796-804. [CrossRef]

28. Dehghani, M.H.; Ghadermazi, M.; Bhatnagar, A.; Sadighara, P.; Jahed-Khaniki, G.; Heibati, B.; McKay, G. Adsorptive removal of endocrine disrupting bisphenol A from aqueous solution using chitosan. J. Environ. Chem. Eng. 2016, 4, 2647-2655. [CrossRef]

29. Lazim, Z.M.; Salmiati; Hadibarata, T.; Yusop, Z.; Nazifa, T.H.; Abdullah, N.H.; Nuid, M.; Salim, N.A.A.; Zainuddin, N.A.; Ahmad, N. Bisphenol A Removal by Adsorption Using Waste Biomass: Isotherm and Kinetic Studies. Biointerface Res. Appl. Chem. 2021, 11, 8467-8481.

30. Balarak, D. Kinetics, Isotherm and Thermodynamics Studies on Bisphenol A Adsorption using Barley husk. Inter. J. ChemTech Res. 2016, 9, 681-690.

31. Olawale Orimolade, B.; Amoo Adekola, F.; Aminat Mohammed, A.; Olayiwola Idris, A.; Damilare Saliu, O.; Yusuf, T. Removal of Bisphenol-A from Aqueous Solution Using Rice Husk Nanosilica: Adsorption Kinetics, Equilibrium and Thermodynamic Studies. J. Appl. Chem. Res. 2018, 12, 8-21.

32. Şimşek, S.; Ulusoy, H.I. Synthesis of a Useful and Economic Polymeric Material for Effective Removal of Bisphenol A. J. Polym. Environ. 2017, 26, 1605-1612. [CrossRef]

33. Xiang, Y.; Yan, H.; Zheng, B.; Faheem, A.; Chen, W.; Hu, Y. E. coli@UiO-67 composites as a recyclable adsorbent for bisphenol A removal. Chemosphere 2021, 270, 128672. [CrossRef] [PubMed] 
34. Li, Q.; Pan, F.; Li, W.; Li, D.; Xu, H.; Xia, D.; Li, A. Enhanced Adsorption of Bisphenol A from Aqueous Solution with 2-Vinylpyridine Functionalized Magnetic Nanoparticles. Polymers 2018, 10, 1136. [CrossRef] [PubMed]

35. Balarak, D.; Ansari, H.; Dashtizadeh, M. Maryam Bazi Synthesis of Graphene Oxide as an Adsorbent for the Removal of Bisphenol A. J. Hum. Environ. Health Promot. 2019, 5, 98-103. [CrossRef]

36. Adak, A.; Bandyopadhyay, M.; Pal, A. Removal of crystal violet dye from wastewater by surfactant-modified alumina. Sep. Purif. Technol. 2005, 44, 139-144. [CrossRef]

37. Adak, A.; Pal, A.; Bandyopadhyay, M. Removal of phenol from water environment by surfactant-modified alumina through adsolubilization. Colloids Surf. A Physicochem. Eng. Asp. 2006, 277, 63-68. [CrossRef]

38. Khobragade, M.; Pal, A. Adsorptive removal of Mn(II) from water and wastewater by surfactant-modified alumina. Desalination Water Treat. 2014, 57, 2775-2786. [CrossRef]

39. Khobragade, M.U.; Pal, A. Fixed-bed column study on removal of Mn(II), Ni(II) and Cu(II) from aqueous solution by surfactant bilayer supported alumina. Sep. Sci. Technol. 2016, 51, 1287-1298. [CrossRef]

40. Khobragade, M.U.; Nayak, A.K.; Pal, A. Solid-Phase Extraction of Cu(II) from Aqueous Solution Using Surfactant-Modified Alumina. J. Hazard. Toxic Radioact. Waste 2017, 21, 04016017. [CrossRef]

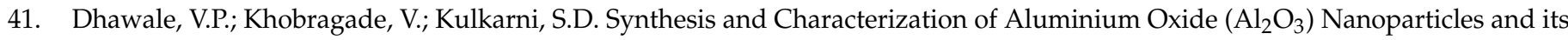
Application in Azodye Decolourisation. Int. J. Environ. Chem. 2018, 2, 10. [CrossRef]

42. Chu, T.P.M.; Nguyen, N.T.; Vu, T.L.; Dao, T.H.; Dinh, L.C.; Nguyen, H.L.; Hoang, T.H.; Le, T.S.; Pham, T.D. Synthesis, Characterization, and Modification of Alumina Nanoparticles for Cationic Dye Removal. Materials 2019, 12, 450. [CrossRef]

43. Banerjee, S.; Dubey, S.; Gautam, R.K.; Chattopadhyaya, M.C.; Sharma, Y.C. Adsorption characteristics of alumina nanoparticles for the removal of hazardous dye, Orange G from aqueous solutions. Arabian J. Chem. 2019, 12, 5339-5354. [CrossRef]

44. Zhang, Y.; Liu, C.; Luo, L.; Shi, Y.; Chen, Y.; Wang, S.; Bian, L.; Jiang, F. One-step hydrothermal synthesis of CTAB-modified SiO 2 for removal of bisphenol A. Water Sci. Technol. 2017, 76, 928-938. [CrossRef] [PubMed]

45. Rovani, S.; Santos, J.J.; Guilhen, S.N.; Corio, P.; Fungaro, D.A. Fast, efficient and clean adsorption of bisphenol-A using renewable mesoporous silica nanoparticles from sugarcane waste ash. RSC Adv. 2020, 10, 27706-27712. [CrossRef]

46. Syarif, D.G.; Prajitno, D.H.; Umar, E. Synthesis of $\mathrm{A}_{2} \mathrm{O}_{3}$ Nanoparticles from Local Bauxite for Water- $\mathrm{A}_{2} \mathrm{O}_{3} \mathrm{Nanofluids}$ egy. J. Phys. Conf. Ser. 2017, 799, 12014. [CrossRef]

47. Meteab, H.S.; Karem, H.A.; Salih, W.K. Synthesis and characterization of nano gamma aluminium oxide from iraqi bauxite using extraction method. ARPN J. Eng. Appl. Sci. 2018, 13, 814-818.

48. Isfahani, T.D.; Javadpour, J.; Khavandi, A.; Dinnebier, R.; Goodarzia, M.; Rezaie, H.R. Mechanochemical synthesis of alumina nanoparticles: Formation mechanism and phase transformation. Powder Technol. 2012, 229, 17-23. [CrossRef]

49. Suchanek, W.L.; Garces, J.M. Hydrothermal synthesis of novel alpha alumina nano-materials with controlled morphologies and high thermal stabilities. CrystEngComm 2010, 12, 2996-3002. [CrossRef]

50. Behera, P.S.; Sarkar, R.; Bhattacharyya, S. Nano Alumina: A Review of the Powder Synthesis Method. Interceram-Int. Ceram. Rev. 2016, 65, 10-16. [CrossRef]

51. Zaki, T.; Kabel, K.; Hassan, H. Preparation of high pure $\alpha-\mathrm{Al}_{2} \mathrm{O}_{3}$ nanoparticles at low temperatures using Pechini method. Ceram. Int. 2012, 38, 2021-2026. [CrossRef]

52. Kango, S.; Kalia, S.; Celli, A.; Njuguna, J.; Habibi, Y.; Kumar, R. Surface modification of inorganic nanoparticles for development of organic-inorganic nanocomposites-A review. Prog. Polym. Sci. 2013, 38, 1232-1261. [CrossRef]

53. Manivasakan, P.; Rajendran, V.; Rauta, P.R.; Sahu, B.B.; Panda, B.K. Direct synthesis of nano alumina from natural bauxite. Adv. Mater. Res. 2009, 67, 143-148. [CrossRef]

54. Chen, F.; Zhao, E.; Kim, T.; Wang, J.; Hableel, G.; Reardon, P.J.T.; Ananthakrishna, S.J.; Wang, T.; Arconada-Alvarez, S.; Knowles, J.C.; et al. Organosilica Nanoparticles with an Intrinsic Secondary Amine: An Efficient and Reusable Adsorbent for Dyes. ACS Appl. Mater. Interfaces 2017, 9, 15566-15576. [CrossRef] [PubMed]

55. Nayab, S.; Farrukh, A.; Oluz, Z.; Tuncel, E.; Tariq, S.R.; Rahman, H.U.; Kirchhoff, K.; Duran, H.; Yameen, B. Design and Fabrication of Branched Polyamine Functionalized Mesoporous Silica: An Efficient Absorbent for Water Remediation. ACS Appl. Mater. Interfaces 2014, 6, 4408-4417. [CrossRef] [PubMed]

56. Jia, Y.F.; Xiao, B.; Thomas, K.M. Adsorption of Metal Ions on Nitrogen Surface Functional Groups in Activated Carbons. Langmuir 2002, 18, 470-478. [CrossRef]

57. Vijayakumar, G.; Tamilarasan, R.; Dharmendirakumar, M. Adsorption, Kinetic, Equilibrium and Thermodynamic studies on the removal of basic dye Rhodamine-B from aqueous solution by the use of natural adsorbent perlite. J. Mater. Environ. Sci. 2012, 3, 157-170.

58. Geyikçi, F. Adsorption of Acid Blue 161 (AB 161) Dye from Water by Multi-walled Carbon Nanotubes. Full-Nanotub. Carbon Nanostructures 2013, 21, 579-593. [CrossRef]

59. Bawa, S.G.; Ahmed, A.S.; Okonkwo, P.C. The study of Thermal effect on the surface properties of Gamma-Alumina synthesed from Kankara Kaolin. Niger. J. Technol. 2016, 35, 66-70. [CrossRef]

60. Paranjpe, K.Y. Alpha, Beta and Gamma Alumina as a catalyst-A Review. Pharma Innov. J. 2017, 6, $236-238$.

61. Rodríguez, J.A.; García, M.F. Synthesis, Properties, and Applications of Oxide Nanomaterials; John Wiley \& Sons: Hobeken, NJ, USA, 2007. 
62. Rahmanpour, O.; Shariati, A.; Nikou, M.R.K. New Method for Synthesis Nano Size $\gamma-\mathrm{Al}_{2} \mathrm{O}_{3}$ Catalyst for Dehydration of Methanol to Dimethyl Ether. Int. J. Chem. Eng. Appl. 2012, 3, 125-128. [CrossRef]

63. Yimin, L.; Dianqing, L.; Pinggui, T.; Yongjun, F. A simple and promoter free way to synthesize spherical $\gamma$-alumina with high hydrothermal stability. Mater. Lett. 2015, 155, 75-77.

64. Bazyari, A.; Mortazavi, Y.; Khodadadi, A.A.; Thompson, L.T.; Tafreshi, R.; Zaker, A.; Ajenifujah, O.T. Effects of alumina phases as nickel supports on deep reactive adsorption of (4,6-dimethyl) dibenzothiophene: Comparison between $\gamma, \delta$, and $\theta$-alumina. Appl. Catal. B Environ. 2016, 180, 312-323. [CrossRef]

65. Ysla, F.A.; Martins, A.R.; Rodrigo Estevam, C.; Cesário, F.d.V.; Adriana, D.B.; Carvalho, L.S. A Simple Way to Produce $\gamma$-Alumina From Aluminum Cans by Precipitation Reactions. Mater. Res. 2016, 19, 977-982.

66. Khosla, E.; Kaur, S.; Dave, P.N. Mechanistic study of adsorption of acid orange-7 over aluminum oxide nanoparticles. J. Eng. 2013, 2013, 593534. [CrossRef]

67. Sharma, Y.C.; Srivastava, V.; Upadhyay, S.N.; Weng, C.H. Alumina nanoparticles for the removal of Ni(II) from aqueous solutions. Ind. Eng. Chem. Res. 2008, 47, 8095-8100. [CrossRef]

68. Afkhami, A.; Saber-Tehrani, M.; Bagheri, H. Simultaneous removal of heavy-metal ions in wastewater samples using nanoalumina modified with 2,4-dinitrophenylhydrazine. J. Hazard. Mater. 2010, 181, 836-844. [CrossRef]

69. Al-Rubayee, W.T.; Abdul-Rasheed, O.F.; Ali, N.M. Preparation of a Modified Nanoalumina Sorbent for the Removal of Alizarin Yellow R and Methylene Blue Dyes from Aqueous Solutions. J. Chem. 2016, 2016, 4683859. [CrossRef]

70. Li, W.; Cao, C.Y.; Wu, L.Y.; Ge, M.F.; Song, W.G. Superb fluoride and arsenic removal performance of highly ordere mesoporous aluminas. J. Hazard. Mater. 2011, 198, 143-150. [CrossRef]

71. Srivastava, V.; Weng, C.H.; Singh, V.K.; Sharma, Y.C. Adsorption of nickel ions from aqueous solutions by nano alumina: Kinetic, mass transfer, and equilibrium studies. J. Chem. Eng. Data 2011, 56, 1414-1422. [CrossRef]

72. Pham, T.D.; Kobayashi, M.; Adachi, Y. Interfacial characterization of $\alpha$-alumina with small surface area by streaming potential and chromatography. Colloids Surf. A 2013, 436, 148-157. [CrossRef]

73. Dovi, E.; Kani, A.N.; Aryee, A.A.; Jie, M.; Li, J.; Li, Z.; Li, Q.; Han, R. Decontamination of bisph en ol A and Congo red dye from solution by using CTAB functionalised walnut shell. Environ. Sci. Pollut. Res. 2021, 28, 28732-28749. [CrossRef]

74. Royer, B.; Cardoso, N.F.; Lima, E.C.; Vaghetti, J.C.P.; Simon, N.M.; Calvete, T.; Veses, R.C. Applications of Brazilian pine-fruit shell in natural and carbonized forms as adsorbents to removal of methylene blue from aqueous solutions-kinetic and equilibrium study. J. Hazard. Mater. 2009, 164, 1213-1222. [CrossRef]

75. Makhlouf, M.; Hamacha, R.; Villièras, F.; Bengueddach, A. Kinetics and thermodynamics adsorption of phenolic compounds on organic-inorganic hybrid mesoporous material. Int. J. Innov. Appl. Stud. 2013, 3, 1116-1124.

76. Tavlieva, M.P.; Genieva, S.D.; Georgieva, V.G.; Vlaev, L.T. Kinetic study of brilliant green adsorption from aqueous solution onto white rice husk ash. J. Colloid Interface Sci. 2013, 409, 112-122. [CrossRef] [PubMed]

77. Xu, J.; Wang, L.; Zhu, Y. Decontamination of Bisphenol A from Aqueous Solution by Graphene Adsorption. Langmuir 2012, 28, 8418-8425. [CrossRef]

78. Zhao, Z.; Fu, D.; Ma, Q. Adsorption Characteristics of Bisphenol A from Aqueous Solution onto HDTMAB-Modified Palygorskite. Sep. Sci. Technol. 2014, 49, 81-89. [CrossRef]

79. Wang, H.; Zhang, H.; Jiang, J.-Q.; Ma, X. Adsorption of bisphenol A onto cationic-modified zeolite. Desalination Water Treat. 2016, 57, 26299-26306. [CrossRef]

80. Yang, Q.; Gao, M.; Luo, Z.; Yang, S. Enhanced removal of bisphenol A from aqueous solution by organo-montmorillonites modified with novel Gemini pyridinium surfactants containing long alkyl chain. Chem. Eng. J. 2016, 285, 27-38. [CrossRef]

81. Li, Y.; Jin, F.; Wang, C.; Chen, Y.; Wang, Q.; Zhang, W.; Wang, D. Modification of bentonite with cationic surfactant for the enhanced retention of bisphenol A from landfill leachate. Environ. Sci. Pollut. Res. 2015, 22, 8618-8628. [CrossRef]

82. Bhatnagar, A.; Anastopoulos, I. Adsorptive removal of bisphenol A (BPA) from aqueous solution: A review. Chemosphere 2017, 168, 885-902. [CrossRef] [PubMed]

83. Liu, C.; Wu, P.; Zhu, Y.; Tran, L. Simultaneous adsorption of $\mathrm{Cd}^{2+}$ and BPA on amphoteric surfactant activated montmorillonite. Chemosphere 2016, 144, 1026-1032. [CrossRef]

84. Vithanage, M.; Mayakaduwa, S.; Herath, I.; Ok, Y.S.; Mohan, D. Kinetics, thermodynamics and mechanistic studies of carbofuran removal using biochars from tea waste and rice husks. Chemosphere 2016, 150, 781-789. [CrossRef] [PubMed]

85. Adeyemo, A.A.; Adeoye, I.O.; Bello, O.S. Adsorption of dyes using different types of clay: A review. Appl. Water Sci. 2017, 7, 543-568. [CrossRef]

86. Gorzin, F.; Abadi, M.B.R. Adsorption of $\mathrm{Cr}(\mathrm{VI})$ from aqueous solution by adsorbent prepared from paper mill sludge: Kinetics and thermodynamics studies. Adsorpt. Sci. Technol. 2018, 36, 149-169. [CrossRef]

87. Liu, S.; Wu, P.; Chen, M.; Yu, L.; Kang, C.; Zhu, N.; Dang, Z. Amphoteric modified vermiculites as adsorbents for enhancing removal of organic pollutants: Bisphenol A and Tetrabromobisphenol A. Environ. Pollut. 2017, 228, 277-286. [CrossRef] [PubMed]

88. Hameed, B.H.; Tan, I.A.W.; Ahmad, A.L. Adsorption isotherm, kinetic modeling and mechanism of 2,4,6-trichlorophenol on coconut husk-based activated carbon. Chem. Eng. J. 2008, 144, 235-244. [CrossRef] 
89. Dayane, J.A.; Hélen, C.R.; Érica, L.O.; Ione, L.S.A.; Nívia, M.M.C.; Túlio, N.M.; Cleide, S.T.A. Characterization of Pequi (Caryocar brasiliense) Shells and Evaluation of Their Potential for the Adsorption of Pb(II) Ions in Aqueous Systems. J. Braz. Chem. Soc. 2016, 27, 616-623.

90. Hind, A.R.; Bhargava, S.K.; McKinnon, A. At the solid/liquid interface: FTIR/ATR-The tool of choice. Adv. Colloid Interface Sci. 2001, 93, 91-114. [CrossRef] 